\title{
ORIGINAL
}

Fawad Maqbool • Fabian Maaß - Johannes Buhl •

Marlon Hahn • Ramin Hajavifard • Frank Walther •

A. Erman Tekkaya • Markus Bambach

\section{Targeted residual stress generation in single and two point incremental sheet forming (ISF)}

Received: 22 October 2020 / Accepted: 8 March 2021 / Published online: 3 May 2021

(C) The Author(s) 2021

\begin{abstract}
The mechanical properties and the operating life of a formed component are highly dependent on the residual stress state. There is always a high magnitude of residual stresses in the components formed by incremental sheet forming (ISF) due to the localized deformation mechanism. Hence, a thorough understanding of the generation of the residual stresses by ISF is necessary. This study investigates the residual stress generation mechanism for two process variants of ISF, i.e., Single Point Incremental Forming (SPIF) and Two Point Incremental Forming (TPIF). This understanding is used to control and targetedly generate the residual stresses to improve the part performance. In this regard, the residual stress state in a truncated cone geometry manufactured using SPIF and disc springs manufactured using TPIF was experimentally analyzed. Validated numerical models for both process variants were developed to study the residual stresses in detail. The residual stress state in SPIF is such that the tool contact side develops tensile residual stresses and the non-contact side undergoes compressive residual stresses. The tool step-down variation was used to control residual stresses and improve the fatigue strength of truncated cones manufactured using SPIF. For TPIF, two different forming strategies were used to analyze the residual stress generation mechanism and the role of
\end{abstract}

F. Maqbool $(\varangle) \cdot$ J. Buhl · M. Bambach

Chair of Mechanical Design and Manufacturing, Brandenburg University of Technology Cottbus-Senftenberg, KonradWachsmann-Allee 17, 03046 Cottbus, Germany

e-mail: fawad.maqbool@b-tu.de

J. Buhl

e-mail: johannes.buhl@b-tu.de

M. Bambach

e-mail: bambach@b-tu.de

F. Maaß · M. Hahn · A. E. Tekkaya

Institute of Forming Technology and Lightweight Components, TU Dortmund University, Baroper Str. 303, 44227 Dortmund, Germany

e-mail: Fabian.Maass@iul.tu-dortmund.de

M. Hahn

e-mail: marlon.hahn@iul.tu-dortmund.de

A. E. Tekkaya

e-mail: Erman.Tekkaya@iul.tu-dortmund.de

R. Hajavifard · F. Walther

Department of Material Test Engineering (WPT), Baroper str. 303, 44227 Dortmund, Germany

e-mail: ramin.hajavifard@tu-dortmund.de

F. Walther

e-mail: frank.walther@tu-dortmund.de

M. Bambach

Advanced Manufacturing, Department of Mechanical and Process Engineering, ETH Zurich, Zurich, Switzerland 
major process parameters. The residual stresses for TPIF are pre-dominantly compressive in both directions of forming tool motion. For both process variants of the ISF process, it is shown that the residual stresses can be beneficially utilized to improve mechanical properties of the components.

Keywords Incremental sheet forming $\cdot$ Mechanism $\cdot$ Residual stresses

\section{Introduction}

Incremental sheet forming (ISF) is a flexible sheet metal forming process for small batch production and rapid prototyping [1]. The two basic configurations of the ISF are Single Point incremental forming (SPIF) and Two Point Incremental Forming (TPIF) as represented in Fig. 1. SPIF is characterized as the forming of a sheet blank by a CNC-controlled hemispherical forming tool with sheet blank clamped in non-workpiece specific tooling without any partial or full tooling. The lack of die ensures high flexibility of the SPIF variant. In the case of TPIF, a full or partial die is added to the opposite side of the forming tool. The full die can either have a positive or negative shape [2].

Due to the localized deformation mechanism of the ISF process, the sheet blank is stretched considerably more than conventional forming processes [3], resulting in a very high magnitude of the residual stresses. This high magnitude of the residual stresses causes high geometric deviations and can reduce the service life of the components [4]. Typically, a high magnitude of the residual stresses is avoided and methodologies are used to decrease residual stress magnitude like post-forming stress-relief annealing [5]. In the current work, an in-depth analysis of the residual stress generation mechanism by ISF is intended. The developed knowledge is aimed to be targetedly used to improve the mechanical properties of formed components (Fig. 2).

Although residual stresses have an impact on geometric accuracy of formed components and their service life, only a limited amount of studies have been reported in the literature that deals with the ISF process and residual stresses. Furthermore, to the knowledge of authors, no study has been reported in the literature that focuses on the targeted utilization of the residual stresses of the ISF process other than the recent studies reported by the authors [6-9]. In the next section, a brief review of the literature dealing with the SPIF process and the residual stresses is presented. In the case of TPIF, no study has still been presented that investigates the effect of process parameters on the residual stresses.

Tanaka et al. [10] used numerical analysis to study residual stresses in parts formed by SPIF. They found that the residual stress decrease by increasing tool diameter and no significant change in the state of the residual stresses occur by changing the feed rate. Radu et al. [11] used the hole-drilling method to analyze residual stresses in a cone and a pyramidal part formed by SPIF. They further developed a cause-effect relationship between residual stresses, geometric accuracy and process parameters of SPIF [12]. It was reported that increasing tool diameter and spindle speed reduces residual stresses, whereas an increase in tool step-down and feed rate leads to higher residual stresses. Residual stress in a variable wall angle cone manufactured by SPIF was analyzed by X-ray diffraction [13]. Shi et al. [14] used hole-drilling method to analyze the residual stresses in incrementally formed $\mathrm{Cu} /$ steel bonded laminates. In all these studies on SPIF, the nature of the reported residual stresses is such that it creates negative springback, i.e., the upper layer in contact with the forming tool undergoes tensile residual stresses and the lower non-contact layer undergoes compressive residual stresses. In a recent study, Maqbool and Bambach [15] analyzed the residual stresses in pyramidal parts by cutting strips along the tool motion and transverse direction. A relationship between process parameters and geometric accuracy was developed by measuring the curvature of the strips.

Different studies have been reported in the literature that analyzes the residual stress generation mechanism for the ISF process. However, a thorough understanding of the residual stresses and their impact on the part

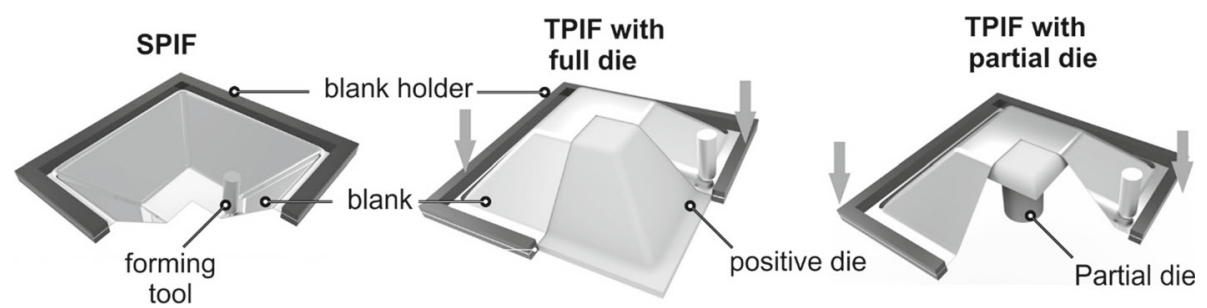

Fig. 1 Common variants of the ISF process 

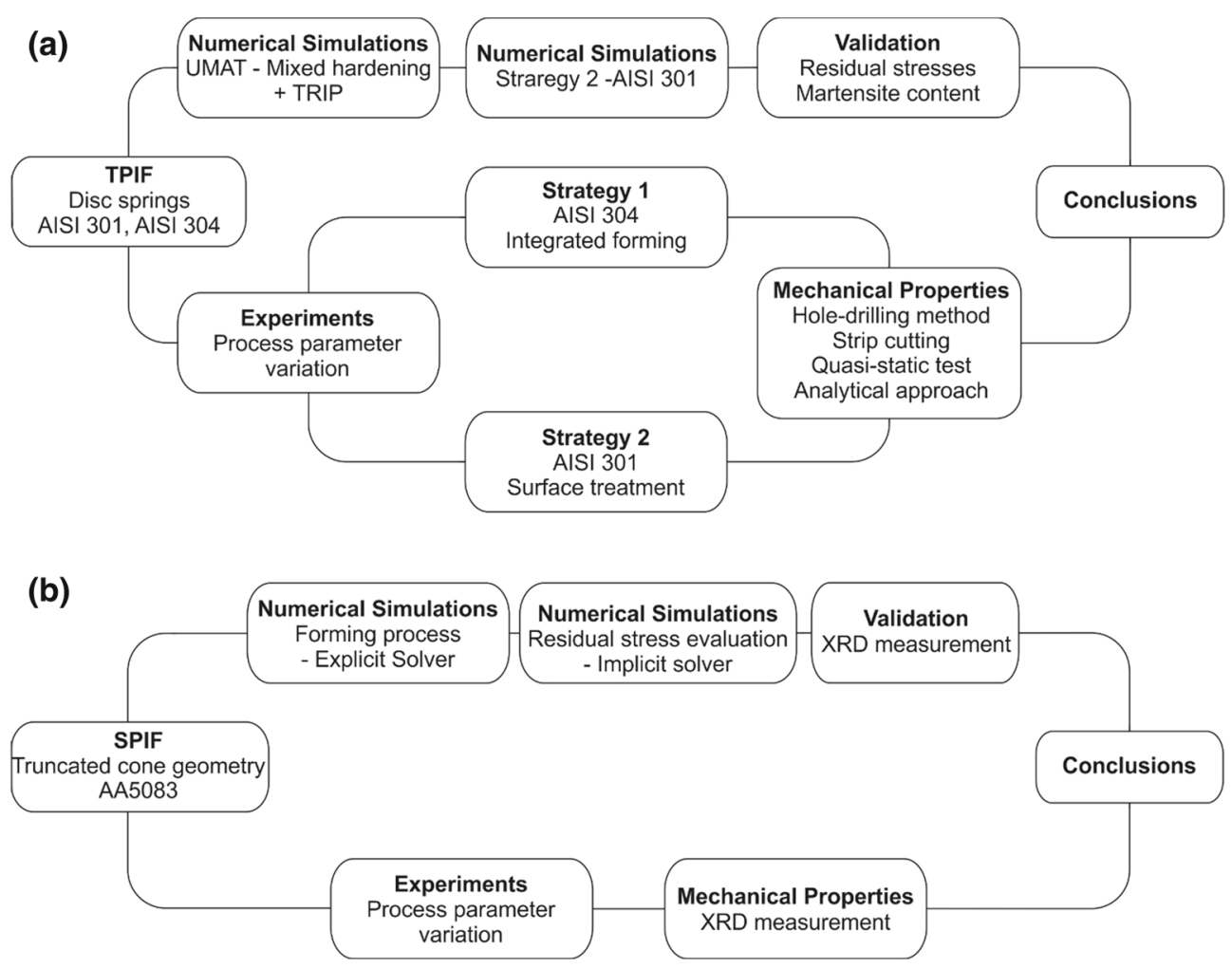

Fig. 2 Flow chart depicting the step-by-step procedure to analyze the residual stresses for a TPIF and $\mathbf{b}$ SPIF variants

performance has not been reported. The main goal of the current work is to develop an understanding of the residual stress generation mechanism for SPIF and TPIF. For SPIF, the common benchmark geometry of a truncated cone was selected. The residual stresses generation mechanism is investigated by changing the tool step-down. It is shown that the residual stresses can be set by varying tool step-down to adjust residual stresses and improve the fatigue life of a truncated cone component. A particular focus is put on TPIF as until now no information is available on the relationship between residual stresses and process parameters. The selected benchmark geometry was disc springs. The geometric features remain similar to that of truncated cone geometry, with the only difference being that of the wall angle, which is significantly smaller for disc spring geometries. For TPIF, two different forming strategies are used to incrementally form and surface treat the disc springs. Residual stresses are then analyzed in these disc springs by the hole-drilling method. In addition, strips along the radial and tangential direction are cut from the disc springs to determine the change in the intensity of the residual stresses due to varying process parameters. It is shown that the residual stresses can be adjusted and targetedly utilized to improve the mechanical properties of the disc springs by selectively varying the process parameters. Similarly, for SPIF, In addition, validated numerical models for both ISF variants are reported that will aid to further extend the results of the current study to new components to achieve a targeted distribution of the residual stresses.

\section{Material and methods}

In the current study, two variants of ISF, i.e., SPIF and TPIF are analyzed. The analysis has been carried out by using different geometries and materials. Therefore, in order to better clarify the adopted procedure for each variant, a flow chart depicting the step-by-step procedure is first presented. In the following sections, a detail description of the methodologies is presented.

For the SPIF process, truncated cone geometries made of the aluminum alloy 5053 are analyzed. Geometrically identical cones are manufactured with different tool step-down increments. The residual stress state in the cone wall is determined experimentally using X-ray diffraction method (XRD) in radial and tangential direction. The forming process is modeled in Abaqus. The material model is built-in Abaqus non-linear/kinematic 
(a)

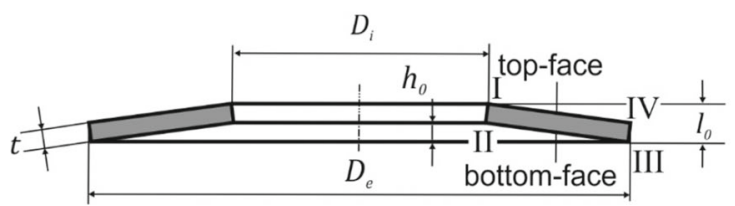

(b) Edge zone with martensite transformation

Fig. 3 a Graphical representation of the investigated disk springs b Process mechanism of TPIF with martensite transformation in the deformed zone

hardening. The forming process is modeled using Abaqus\Explicit@. To evaluate the residual stress state, the unclamping process is modeled subsequently using AbaqusImplicit ${ }^{\circ}$. The numerical model is validated by comparing experimentally and numerically measured residual stresses.

For TPIF, disc springs geometry and two stainless steels AISI 301 and AISI 304 are selected. Further, the TPIF experiments are performed by varying the process parameters and using two different forming strategies, referred to as strategy 1 and strategy 2 . For strategy 1 , TPIF is used as an integrated forming approach, i.e., disk spring forming and residual stress generation are carried out in a single step by using AISI 304. For strategy 2, TPIF is used as a surface treatment approach, i.e., conventionally formed disc springs from AISI 301 are procured from a commercial supplier and are surface treated to induce the residual stresses. Further, different methodologies are used to characterize the mechanical properties and the residual stresses. In addition, a userdefined material (UMAT) based on non-linear isotropic/kinematic hardening law and coupled Olson-Cohen model to model the TRIP effect is implemented in Abaqus ${ }^{\circledR}$ standard. The numerical simulation is performed for strategy 2 using AISI 301. The numerical model is validated by comparing experimentally and numerically measured residual stresses and martensite content.

\subsection{Experimental set-up of TPIF}

The selected geometry to be formed by the TPIF variant was disk springs. The material used for the manufacturing of the disc springs was AISI 301 and AISI 304 stainless steel. The schematic diagram of a disk spring representing the major geometric features of the disc springs is presented in Fig. 3. $D_{e}$ and $D_{i}$ represent the outer and inner diameter of the disk spring, whereas $t, l_{0}$ and $h_{0}$ are the thickness, free height and the cone height of the disk spring, respectively. All disk spring geometries are identified by their respective dimensions according to Fig. 3a and are represented by the term $D_{e} / D_{i} / t$. Further, the two sides of the disk springs are marked as top and bottom face as shown in Fig. 3a.

In a previous publication [7], analysis to targetedly use the residual stress of ISF was carried out by taking disk spring geometry as a benchmark and it was reported that the TPIF with a negative die is the most suitable variant to incrementally form the disk springs. Similarly, the goal of the current study is to further extend the developed knowledge and completely understand the residual stress generation mechanism for the TPIF variant. In this regard, two different strategies based on TPIF with a negative die are used to form and surface treat the disk springs.

\subsubsection{Set-up of strategy 1}

Strategy 1 is based on residual stress generation and disk spring forming by TPIF in a single step. In this strategy, the deep rolling-like effect is replicated by the forming tool when it pushes the sheet blank into a negative die (see Fig. 3b). The disk springs of dimension $80 / 50 / 0.8 \mathrm{~mm}$ were incrementally formed from sheet blanks of AISI 304.The magnitude of the residual stresses is further aided by martensite transformation in the deformed zone, as the selected materials for disk spring manufacturing exhibit transformation-induced plasticity (TRIP) effect. As a result, high compressive residual stresses are generated on the bottom face during TPIF. The compressive residual stresses have a positive effect on spring forces and fatigue life [16]. A small hole is cut in the center of the sheet blank for accurate positioning. After forming, a trimming operation using laser cutting was used to generate the final disk spring geometry. A spherical tool path was used to incrementally form the disk springs. The schematic of strategy 1 and the experimental setup is presented in Fig. 4a and Fig. 3b. 
Strategy 1

(a)

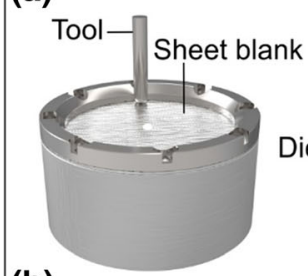

(b)

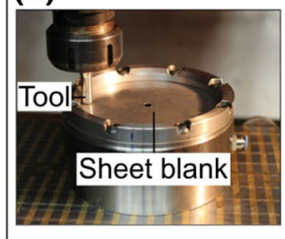

Strategy 2

(c)
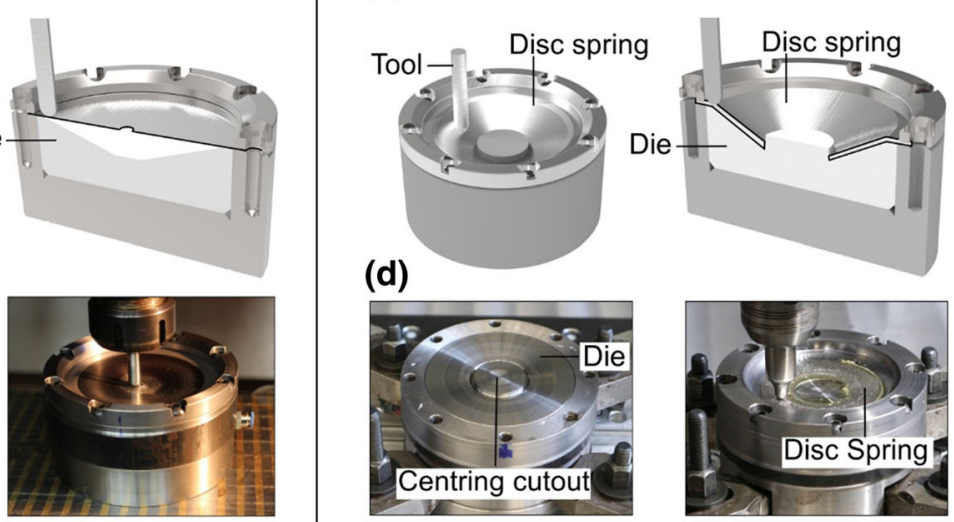

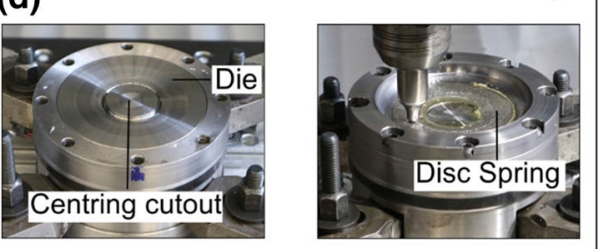

Fig. 4 a Schematic and $\mathbf{b}$ Experimental set-up of strategy $1 \mathbf{c}$ Schematic and $\mathbf{d}$ Experimental set-up of strategy 2

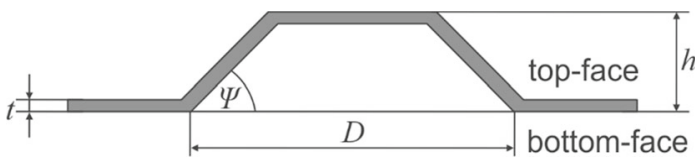

Fig. 5 Dimensions of truncated cone geometry

\subsubsection{Set-up of strategy 2}

Strategy 2 uses ISF as an alternative surface treatment approach. The conventionally formed disk spring is clamped between a die and a frame by using a centering cut-out, so that the whole surface of the disk spring is available for the forming tool. However, the areas near to the cut-out cannot be surface treated due to a danger of collision between the cut-out and forming tool. The schematic and the experimental set-up is presented in Fig. $4 \mathrm{c}$ and d. Disk springs of the material AISI 301 and dimension 112/57/3 mm are surface treated using this approach. The selected process parameters are a critical factor in determining the end residual stress state. Therefore, experiments were performed by varying the important process parameters, i.e., tool diameter $(5,10$, $12.5 \mathrm{~mm})$, tool step-down $(0.05,0.1,0.2 \mathrm{~mm})$ and the contact force $(400,800,1100 \mathrm{~N})$. To realize the variation of the contact pressure, the same experimental set-up is used with an ABB® IRB6700 robot to achieve the force-controlled movement of the forming tool.

\subsection{Experimental set-up of SPIF}

The selected geometry for the SPIF process is a truncated cone geometry. These geometries can be used as a pedestal or countersunk. The geometric features remain similar to that of disk spring geometry, with the only difference being that of the wall angle, which is significantly large for truncated cone geometries ( $\Psi$ $\left.=45^{\circ}\right)$ as compared to disk springs $\left(\Psi=6.1 .^{\circ}\right)$. In previous publications during the manufacturing of the truncated cone geometries, it was noted that the residual stresses are dependent on the used process parameters and by changing process parameters, residual stress can be adjusted. In the current study, the formation and development of residual stresses in the SPIF process under the influence of changing process parameters and the accompanying deformation mechanism is investigated. The goal is to achieve a targeted distribution of the residual stresses in the truncated cone geometries. In this regard, wrought aluminum alloy AA5083 in H111 condition with an initial sheet thickness $t_{0}=1 \mathrm{~mm}$ was used to manufacture the truncated cones. The manufactured truncated cones have a cone wall height of $h=45 \mathrm{~mm}$. The wall angle is $\Psi=45^{\circ}$, the truncated cone diameter is $D=140 \mathrm{~mm}$. These geometric parameters are represented in the schematic drawing in Fig. 5 .

The single point incremental forming process is carried out using a conventional 5-axis milling machine DMG Mori ${ }^{\circledR}$ DMU 50. The driven forming tool $\left(\theta_{\text {Tool }}=300 \mathrm{RPM}\right)$ with a spherical tool tip and the tool radius $D_{\text {Tool }}=15 \mathrm{~mm}$ is moved along a bidirectional tool path with a tool feed $v_{\text {Tool }}=1500 \mathrm{~mm} / \mathrm{min}$ and 


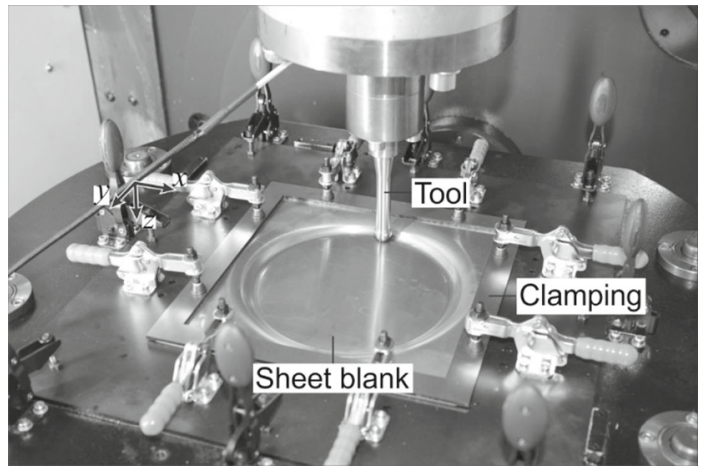

Fig. 6 Single point incremental forming experimental setup

an equidistant tool step-down $\Delta z$. The edges of the metal sheet are clamped during the forming process. To generate different residual stress states, experiments were performed by changing tool step-down $(1.875,3.75$ and $5.625 \mathrm{~mm}$ ) and keeping other parameters constant. Deep-drawing oil Castrol® Iloform PN 226 was used to lubricate the sheet blank surface. The SPIF setup is shown in Fig. 6.

\subsection{Residual stress measurements methods}

Two methodologies are used to measure the residual stresses in incrementally formed parts from SPIF and TPIF variants in the current study. A description of each methodology is presented.

\subsubsection{Hole-drilling method}

The hole-drilling method was used to measure the residual stresses in the disk springs according to ASTM E83713a. The method is based on drilling a hole into specimen and measuring the released strain and converting them into residual stresses. The equipment used for the hole-drilling method consists of a testing rig and strain acquisition system (Sintech Technology) as shown in Fig. 7b. During testing, it was made sure that all measurements are taken at a fixed location for all the disk springs as shown in Fig. 7a. A drill bit of $0.8 \mathrm{~mm}$ was used to drill into the specimen and the drilling steps were automatically adjusted by the testing system software. The released strains are measured using strain-gauge rosette and are converted to stresses by the system software by using Eq. 1 [14]. A value of -0.0845 and -0.0235 was used for A and B, respectively, as provided by the testing system supplier.

$$
\begin{aligned}
& \sigma_{r r}=\mathrm{E}\left\{\frac{\varepsilon_{r r}+\varepsilon_{t t}}{4 A}-\frac{1}{4 B} \sqrt{\left(\varepsilon_{r r}-\varepsilon_{y y}\right)^{2}+\left[2 \varepsilon_{r t}-\left(\varepsilon_{r t}+\varepsilon_{r t}\right)\right]^{2}}\right\} \\
& \sigma_{t t}=\mathrm{E}\left\{\frac{\varepsilon_{r r}+\varepsilon_{t t}}{4 A}+\frac{1}{4 B} \sqrt{\left(\varepsilon_{r r}-\varepsilon_{t t}\right)^{2}+\left[2 \varepsilon_{r t}-\left(\varepsilon_{r t}+\varepsilon_{r t}\right)\right]^{2}}\right\}
\end{aligned}
$$

\subsubsection{XRD}

The residual stresses in the truncated cones are measured experimentally near the surface using X-ray diffraction [17]. The residual stresses are evaluated in the selected point in the center of the formed cone wall at a height of $h_{m}=22.5 \mathrm{~mm}$ (middle of the cone wall). The residual stresses are evaluated on the tool side and the tool-averted side in tangential $\sigma_{t}$ and radial $\sigma_{r}$ direction as in Fig. 8b. The strain analysis is based on the determination of the interplanar distance $d_{(h k l)}$ ( $h k l$-Miller indices) according to the Bragg law as shown in Fig. 8a.

$$
n \cdot \lambda=2 \cdot d_{\{h k l\}} \cdot \sin \theta
$$

where $n$ is the order of diffraction of the interference $(h k l), \lambda$ is the wavelength and $\theta$ is its Bragg angle. The interplanar grid spacing for different sample orientations is measured according to the tensor character of 
(a)

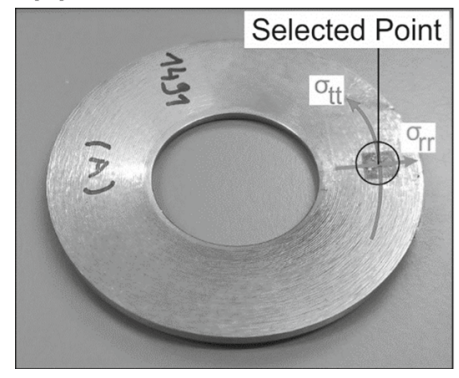

(b)

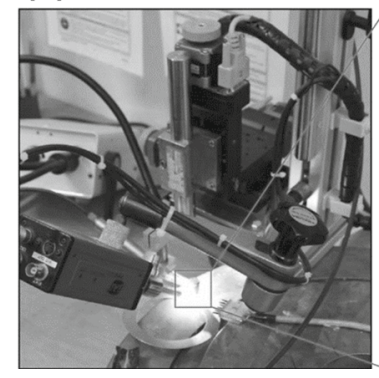

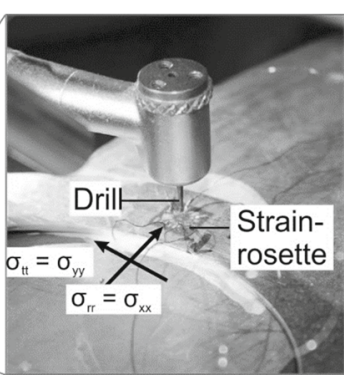

Fig. 7 a The selected point on the disk springs for residual stress measurement b Experimental set-up of measuring residual stresses in the disk springs by hole-drilling method
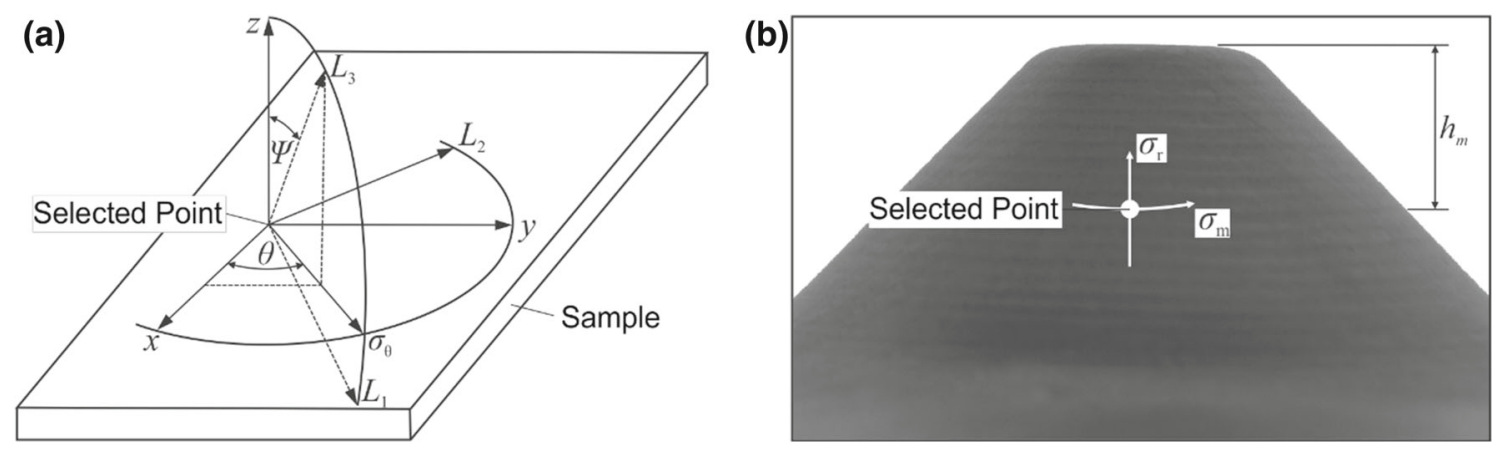

Fig. 8 a XRD measurement; $\sin ^{2} \Psi$ method b Experimental cone geometry with measuring point

strains and stresses. The stresses are calculated using the $\sin ^{2} \Psi$ method [18]. Cr-K $\alpha$ radiation $(\lambda=0,2291 \mathrm{~nm})$ with a mean penetration depth of $\tau=7 \mu \mathrm{m}$ is used. The $2 \theta$ angle has a range of $-42^{\circ}-42^{\circ}$ ( $\pm 3^{\circ}$ oscillation). The exposure time is $t=20 \mathrm{~s}$ per step and the collimator diameter is $D_{\text {Collimator }}=2 \mathrm{~mm}$. The reflection profiles are recorded at 211-plane with for 9 tilts with $\Psi$-inclination angles $0^{\circ}, \pm 19.5^{\circ}, \pm 28.2^{\circ}, \pm 35.4^{\circ}, \pm 42^{\circ}$. The peak evaluation is done using the X3000 V1.2.3 software and cross correlation. The elastic constants are determined to $s_{1}(211)=2,86 \times 10-6 \mathrm{MPa}$ und $1 / 2 s_{2}(211)=10,9610-6 \mathrm{MPa}$. Residual stress components in the measuring point are evaluated in radial and meridional direction $\left(\theta_{r}=0^{\circ}, \theta_{m}=90^{\circ}\right)$.

\subsection{Investigation of the residual stresses by strip cutting}

\subsubsection{TPIF}

To investigate the magnitude of the residual stresses, small strips were cut along the radial and tangential direction of the disk springs, which were surface treated from strategy 2 by varying the process parameters. The disk spring was laser cut by using a TRUMPF® GmbH TruLaser Cell 7040 laser cutting center. The dimension of the radially cut strips was $24 \times 10 \mathrm{~mm}$, whereas the tangentially cut strips were $10 \mathrm{~mm}$ wide, with an outer and inner diameter of 90 and $80 \mathrm{~mm}$, respectively. The tangentially cut strips were further cut along the radial direction. In the case of radial strips, a curvature will appear along the strips, which is directly proportional to the magnitude of the residual stresses in the strips. The circular strips will open or close depending on the magnitude of the residual stresses (Fig. 9c). By measuring the curvature of radial strips and respective opening/closing of the tangential strips, the relation between the process parameters and residual stresses is analyzed.

Furthermore, disk compression tests were carried out to determine the changes in the spring forces due to residual stresses. The disk springs were compressed between two flat plates on a universal testing machine. The spring forces and the residual stress state of the incrementally formed and conventional disk springs were compared. 
(a)

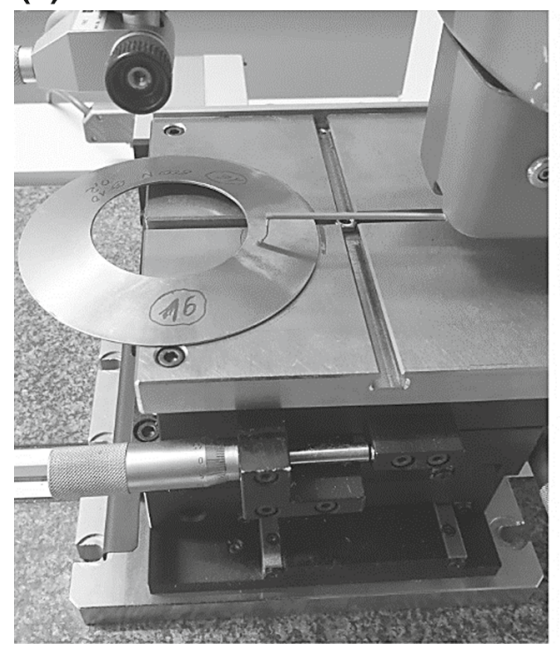

(b)

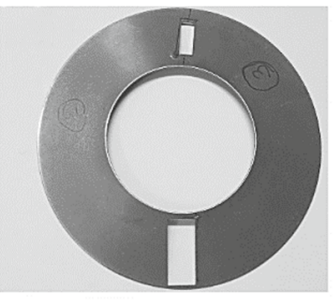

(c)

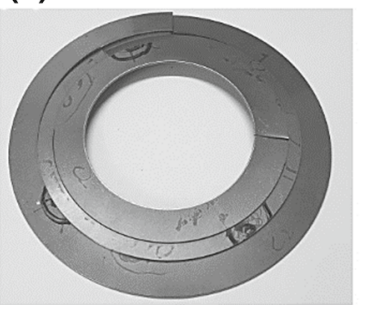

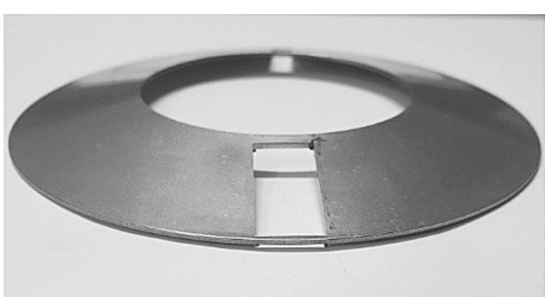

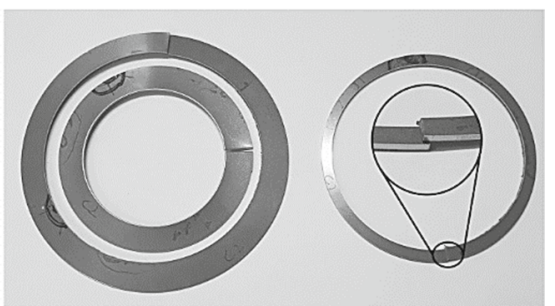

Fig. 9 a Measurement of the disk spring contour b Radial and $\mathbf{c}$ Tangential cut strips from the disk spring

\subsection{Numerical modeling}

\subsubsection{TPIF numerical model}

To arrive at an accurate description of the residual stresses, the process mechanics and material response should be accurately captured by the numerical model and selected constitutive model. The ISF process involves a constant cyclic bending/unbending deformation mechanism. In addition, the selected stainless steel AISI 301 exhibits the TRIP effect. Hence, to accurately capture these effects, non-linear isotropic/kinematic hardening [19] was coupled with the Olson-Cohen model to capture residual stresses accurately by taking into consideration the TRIP effect. The simulation of the TPIF process is performed for strategy 2 . The behavior of the AISI 301 steel was modeled by using two phases,i.e., austenite and martensite. A linear rule of mixture was used to calculate the total stresses. Although, it is a simplification, but it provides a solid base to study the residual stresses in detail. The two phases are as follows:

- volume fraction of austenite represented as $\left(1-f_{\alpha^{\prime}}\right)$

- The transformed martensite volume fraction $f_{\alpha^{\prime}}$

A user-defined material (UMAT) was developed and implemented in commercial FE-code Abaqus/Implicit ${ }^{\circledR}$. The numerically implemented set of equations, i.e., constitutive model to describe the mixed hardening law and transformation kinetics for the martensitic are presented. In addition, the numerical set-up of model for TPIF of disk springs and respective material parameter identification scheme is presented.

Constitutive law The flow stress is a combination of each phase calculated as:

$$
\sigma_{f}=\sigma_{y \gamma}\left(1-f_{\alpha^{\prime}}\right)+\sigma_{y \alpha^{\prime}} f_{\alpha^{\prime}}
$$

where $\sigma_{y \gamma}$ and $\sigma_{y \alpha^{\prime}}$ are the flow stress of the austenite and martensite phase, respectively. Similarly, the elastic modulus and poison's ratio is calculated as a combination of each constituent phase. The Von-Mises yield criterion combined with a non-linear isotropic/kinematic hardening is used for the elastic-plastic response of the material. The yield function is described as follows:

$$
F=\sigma_{\mathrm{eq}}-\sigma_{0}-R
$$

in Eq. (4), $\sigma_{\mathrm{eq}}$ is the equivalent von-Mises stress, $\sigma_{0}$ is the initial yield stress and $R$ controls the isotropic hardening. The $\sigma_{e q}$ is derived as:

$$
\sigma_{\mathrm{eq}}=\sqrt{\frac{3}{2}\left(S_{i j}-X_{i j}\right)\left(S_{i j}-X_{i j}\right)}
$$


Here $S_{i j}, X$ represent the deviatoric part of the stresses and kinematic hardening as a function of plastic strain $\varepsilon_{i j}^{\mathrm{p}}$, respectively.

$$
\begin{aligned}
& R=Q_{0}\left(1-\exp \left(-b \varepsilon_{\mathrm{eq}}^{p}\right)\right) \\
& d X_{i j}=\frac{2}{3} \chi d \varepsilon_{i j}^{p}-\omega X_{i j} d p
\end{aligned}
$$

The $Q_{o}, b, \omega$ and $\chi$ are the material constants and $d p$ define the cumulated plastic strain. By using the consistency conditions, the plastic multiplier is calculated as [20]:

$$
d=\sqrt{\frac{2}{3} d \varepsilon_{i j}^{p} d \varepsilon_{i j}^{p}}=\frac{3 \mu\left(\left(S_{i j}-X_{i j}\right) d \varepsilon_{i j}\right.}{\sigma_{\mathrm{eq}}(3 \mu+\chi+H)-\frac{3}{2} \sigma_{\mathrm{eq}} \omega\left(S_{i j}-X_{i j}\right) X_{i j}}=A_{i j} d \varepsilon_{i j}, H=Q_{0} b \exp \left(-b \varepsilon_{\mathrm{eq}}^{p}\right)
$$

The stress increment is calculated as

$$
\begin{aligned}
d \sigma_{i j} & =C_{i j k l}\left(d \varepsilon_{k l}-d \varepsilon_{k l}^{p}\right) \\
& =C_{i j k l}\left(d \varepsilon_{k l}-d \frac{3}{2} \frac{\left(S_{k l}-X_{k l}\right)}{\sigma_{\mathrm{eq}}}\right) \\
& =C_{i j k l}\left(d \varepsilon_{k l}-\frac{3}{2} \frac{\left(S_{k l}-X_{k l}\right)}{\sigma_{\mathrm{eq}}} A_{m n} \varepsilon_{m n}\right)
\end{aligned}
$$

With $\sigma_{i j}=l_{i j m n}^{\mathrm{ep}} d \varepsilon_{m n}$, the mixed hardening model has the elasto-plastic modulus:

$$
l_{i j m n}^{\mathrm{ep}}=C_{i j k l}\left(I_{k l m n}-\frac{3}{2} \frac{\left(S_{k l}-X_{k l}\right)}{\sigma_{\mathrm{eq}}} A_{m n}\right)
$$

Martensitic transformation criterion The Olson-Cohen model is the most commonly utilized model to describe the TRIP effect as a function of plastic strains. The proposed sigmoidal function to model the transformation kinetics is [21]:

$$
f_{\alpha^{\prime}}=1-\exp \left\{-\beta_{0}\left(1-\exp \left(-\xi \varepsilon_{\mathrm{eq}}^{p}\right)^{n}\right)\right\}
$$

With increasing plastic strain, the shear-band formation rate is governed by the parameter $\xi$. This parameter in turn is dependent on the stacking fault energy. The possibility of martensite nucleation is controlled by the parameter $\beta_{0}$, which in turn depend on the chemical driving force of the transformation $\gamma \rightarrow \alpha^{\prime}$. The term $n$ is used as a fitting variable and its value is mostly taken as 2 [4]. The transformation rate for this model is mathematically represented as:

$$
\frac{d f_{\alpha^{\prime}}}{d \varepsilon}=-\frac{n \xi\left(1-f_{\alpha^{\prime}}\right) \ln \left(1-f_{\alpha^{\prime}}\right)}{\exp \left(\xi \varepsilon_{\mathrm{eq}}^{\mathrm{p}}\right)-1}
$$

The implemented incremental formulation to calculate the martensite formation:

$$
\begin{gathered}
f_{s b}=\xi\left(1-f_{s b}\right) \dot{\varepsilon}_{\mathrm{eq}}^{p} \\
\mathcal{M}=\xi \beta_{0} n\left(f_{s b}\right)^{n-1}\left(1-f_{s b}\right) \\
f_{n m}=M\left(1-f_{n m}\right) \dot{\varepsilon}_{e q}^{p} \\
V_{n m}=V_{a 0} f_{n m}
\end{gathered}
$$

where $f_{s b}, f_{n m}$ are the normalized shear band and newly formed martensite volume fraction. The constitutive framework provides the plastic strain increment. 
(a)

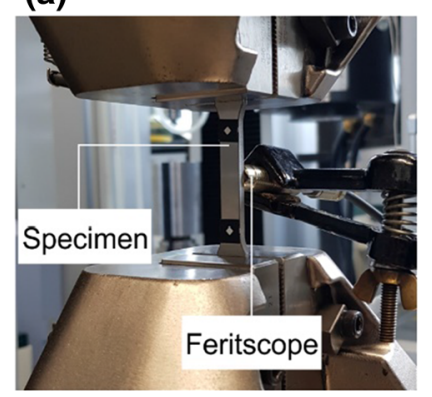

(c)

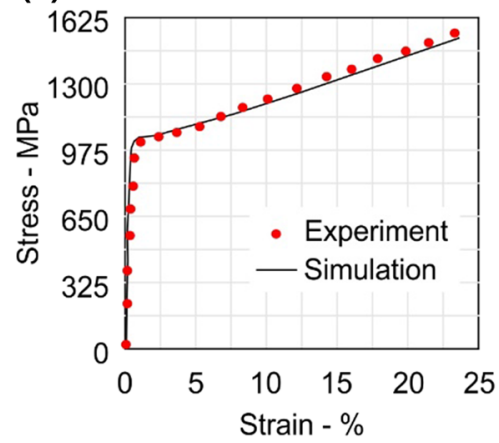

(b)
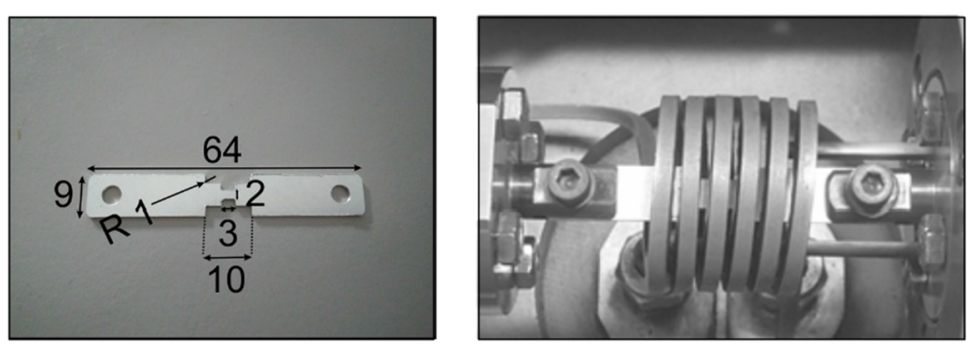

(d)

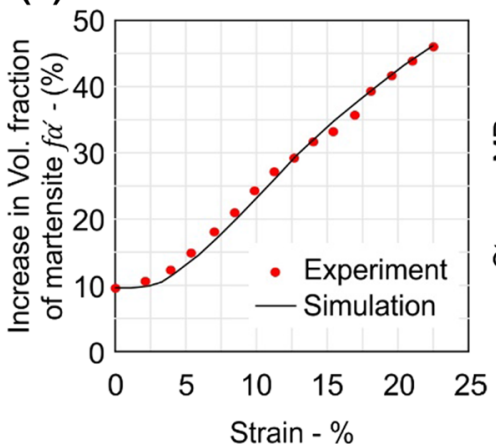

(e)

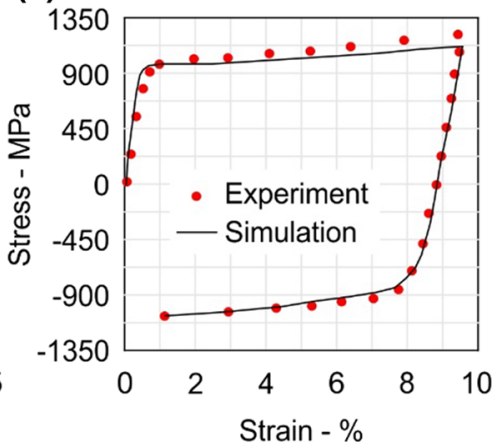

Fig. 10 a Tensile test with online Feritscope measurements b Cyclic test specimen clamped in dilatometer c Numerical and experimental curve comparison for tensile test data, $\mathbf{d}$ Numerical and experimental martensite evolution as a function of plastic strain e Numerical and experimental cyclic stress-strain response

Table 1 Identified material parameters for AISI 301

\begin{tabular}{llllllll}
\hline$\sigma_{y_{0}, \gamma}$ & $Q_{o, \gamma}$ & $b_{\gamma}$ & $E_{\gamma}$ & $v_{\gamma}$ & vol $_{\gamma_{0}}$ & $\chi_{\gamma}$ & $\omega_{\gamma}$ \\
\hline $850 \mathrm{MPa}$ & $302.7 \mathrm{MPa}$ & 19.97 & $188 \mathrm{GPa}$ & 0.3 & $90 \%$ & $11,680.5 \mathrm{MPa}$ & 450 \\
\hline$\sigma_{y_{0}, \alpha^{\prime}}$ & $Q_{o, \alpha^{\prime}}$ & $b_{\alpha^{\prime}}$ & $E_{\alpha^{\prime}}$ & $v_{\alpha^{\prime}}$ & $v o l_{\alpha_{0}^{\prime}}$ & $\chi_{\alpha^{\prime}}$ & $\omega_{\alpha^{\prime}}$ \\
\hline $1460 \mathrm{MPa}$ & $1005 \mathrm{MPa}$ & 10.22 & $217 \mathrm{GPa}$ & 0.28 & $9.5 \%$ & $11,680.5 \mathrm{MPa}$ & 450 \\
\hline
\end{tabular}

Material parameters and set-up of the numerical model To determine the optimized set of material parameters, online Feritscope measurements were coupled with the tensile tests. In addition, cyclic tension-compression test was carried out using a dilatometer. The unknown material parameters were determined by inverse FEapproach. The experimental set-up of the tensile test with online Feritscope measurement is presented in Fig. 10a. The cyclic tests were carried out in a deformation dilatometer DIL-805A with a especially designed test specimen to avoid buckling during compression. The dimension of the specimen and the experimental set-of the cyclic tests is presented in Fig. 10b. For optimization, numerical calculations were carried out on the single 8-node linear brick element, i.e. C3D8 (full integration), to achieve computational efficiency. Figure 10 presents a comparison of tensile test data, martensitic evolution and cyclic stress-strain response for experiments and simulations for the optimized set of parameters. A good match is found.

The martensite evolution in Fig. 10b corresponds to the tension test data, i.e., Fig. 10b. The optimized values are 3.65, 0.73 and 1.97 for $\xi, \beta_{0}$ and $n$, respectively. The calculated material parameters are listed in Table 1 . A Young's modulus of $217 \mathrm{~s}$ and $188 \mathrm{MPa}$ is considered for the austenite and martensitic phase, respectively [22]. Furthermore, an initial volume fraction of martensite was $9.5 \%$ measured by Feritscope.

The numerical model according to strategy 2 along with the determined material parameter is presented in Fig. 11. A rigid material was selected for the die and forming tool of $10 \mathrm{~mm}$ diameter. The dimensions of the disk spring is $112 / 57 / 3 \mathrm{~mm}\left(D_{e} / D_{i} / t\right)$. After each loop, the tool moves down $0.4 \mathrm{~mm}$. The commercial CAD software Pro/e Creo® was used to generate the tool path, which was imported into numerical model as respective co-ordinates in the $x, y$ and $z$ direction. 


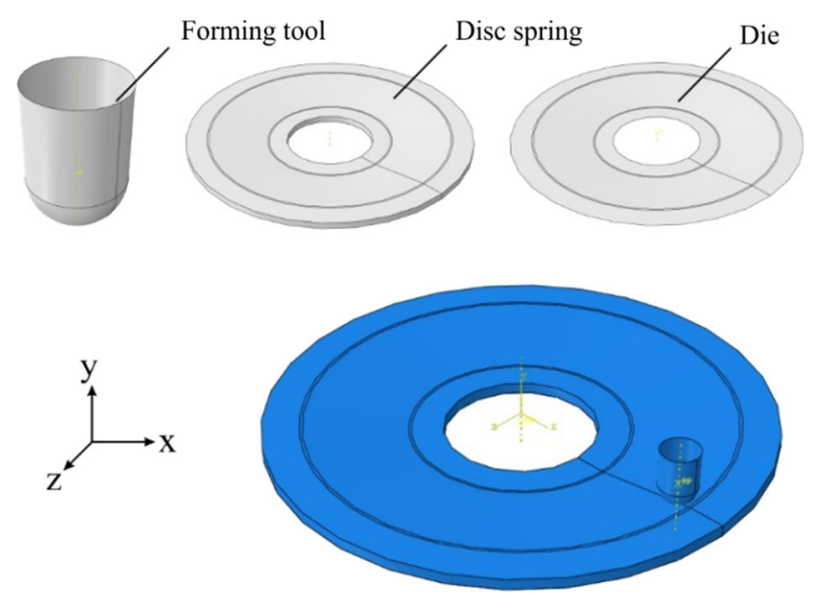

Fig. 11 The numerical set-up of the ISF process

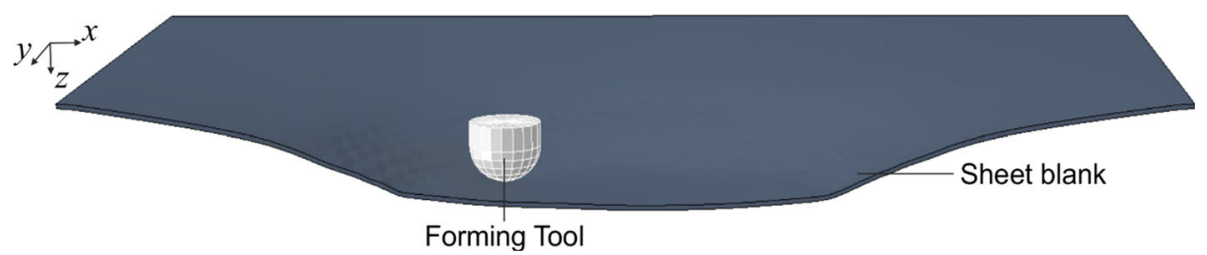

Fig. 12 The numerical model of the SPIF process

\subsubsection{SPIF numerical model}

The numerical process model used by the Abaqus simulation software consists of the rigid forming tool and the elastic-plastic sheet metal meshed with solid elements (C3D8I) of edge length size $1 \mathrm{~mm}$ and 5 elements along the sheet thickness (Fig. 12). An explicit time integration including mass scaling (factor $10^{3}$ ) with a stable time step of $1 \times 10^{-06} \mathrm{~s}$ was used. The material model for the sheet metal is built-in Abaqus ${ }^{\circledR}$ combined hardening model. The numerical simulation begins with a process simulation in Abaqus/Explicit to evaluate the forming process, followed by a subsequent implicit simulation to evaluate the residual stresses after unclamping. A penalty contact is used for the forming tool and sheet.

The combined isotropic-kinematic hardening model also includes the possibility of cyclic hardening, as it occurs with cyclically loaded parts. The model is based on Lemaitre and Chaboche [23] as described above. The AA5083 base material was characterized using the in-plane torsion test as shown in Fig. 13. The cyclic hardening parameters are determined inversely using the cyclic loading test results in a single-element test. These determined material parameters were shown in Table 2. The parameters are used to set-up a numerical model. The experimental and numerical results are shown in Fig. 13. The initial flow stress of the material was determined to be $\sigma_{f, 0}=165 \mathrm{MPa}$.

\section{Results and discussion}

\subsection{Residual stress generation mechanism}

\subsubsection{TPIF}

In strategy 1, ISF is used as an integrated forming approach. The disk springs of dimension 80/50/0.8 mm were incrementally formed from sheet blanks of AISI 304. In strategy 2, ISF is used as an alternative surface treatment approach. The disk springs of dimension 112/57/3 $\mathrm{mm}$ and AISI 301 steel were incrementally surface treated. The hole-drilling method was used to measure the residual stresses in the disk springs. The measured values of the residual stresses along the depth of the hole generated by hole-drilling method for both strategies in the radial and transverse directions are plotted in Fig. 14. 


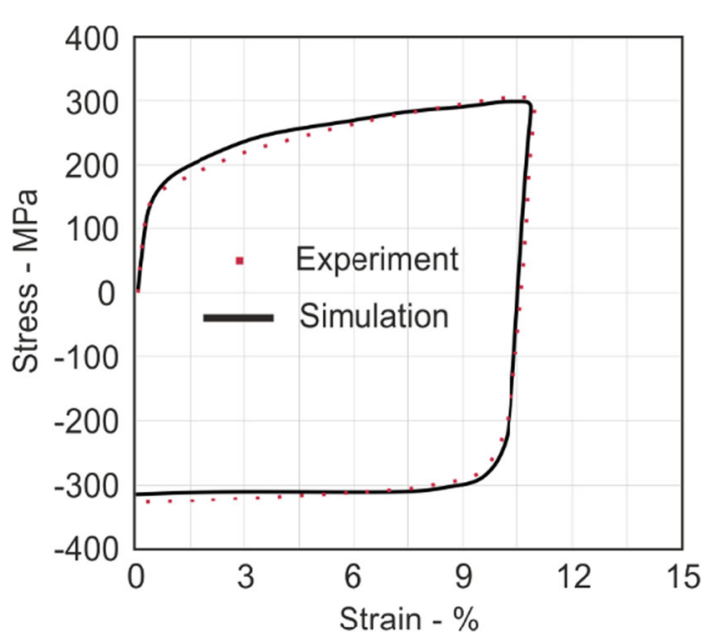

Fig. 13 Material characterization of AA5083

Table 2 Identified material parameters AA5083

\begin{tabular}{lllllll}
\hline$\sigma_{y_{0}, \gamma}$ & $Q_{o, \gamma}$ & $b_{\gamma}$ & $E_{\gamma}$ & $v_{\gamma}$ & $\chi_{\gamma}$ & $\omega_{\gamma}$ \\
\hline $165 \mathrm{MPa}$ & $83 \mathrm{MPa}$ & 9.88 & $73 \mathrm{GPa}$ & 0.33 & $30,000 \mathrm{MPa}$ & 330 \\
\hline
\end{tabular}

(a)

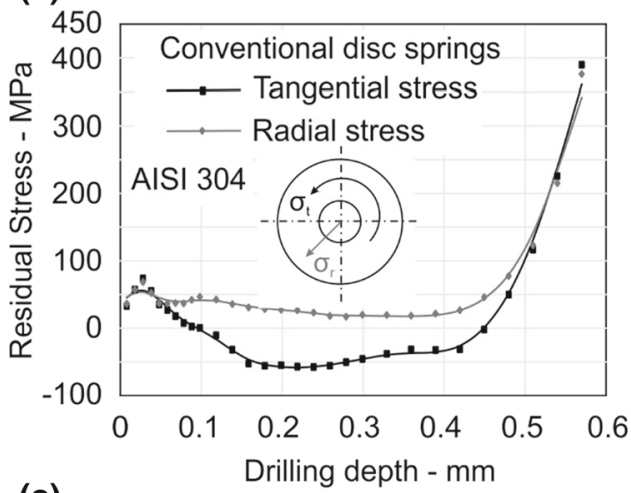

(c)

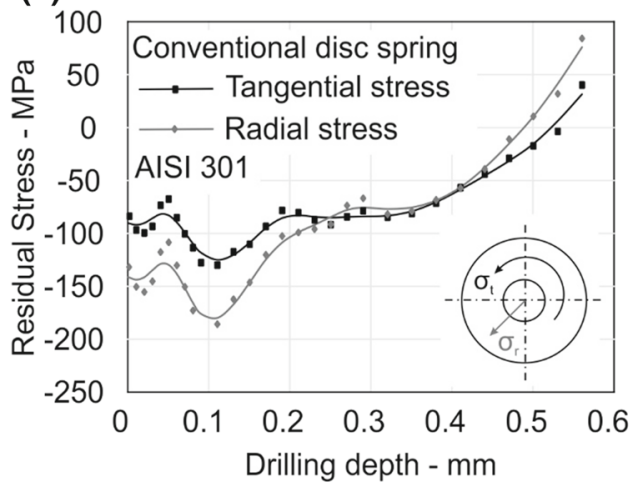

(b)

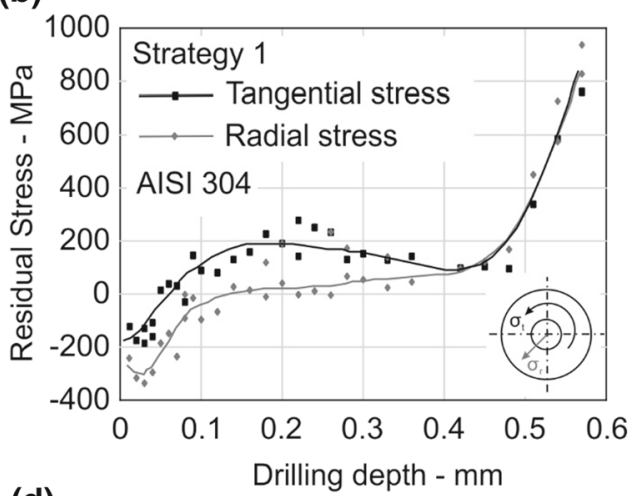

(d)

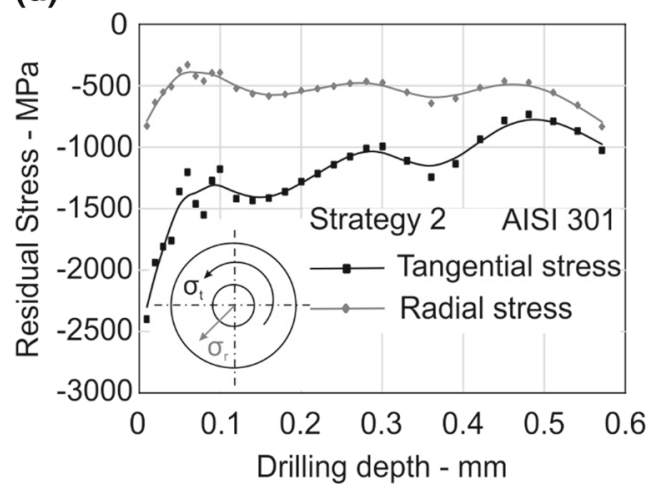

Fig. 14 Radial and tangential components of the residual stresses measured in the disk spring manufactured using a Conventional forming-AISI304 $\mathbf{b}$ ISF as an integrated forming approach-Strategy $1 \mathbf{c}$ Conventional forming-AISI301 d ISF as an alternative surface treatment approach-Strategy 2 

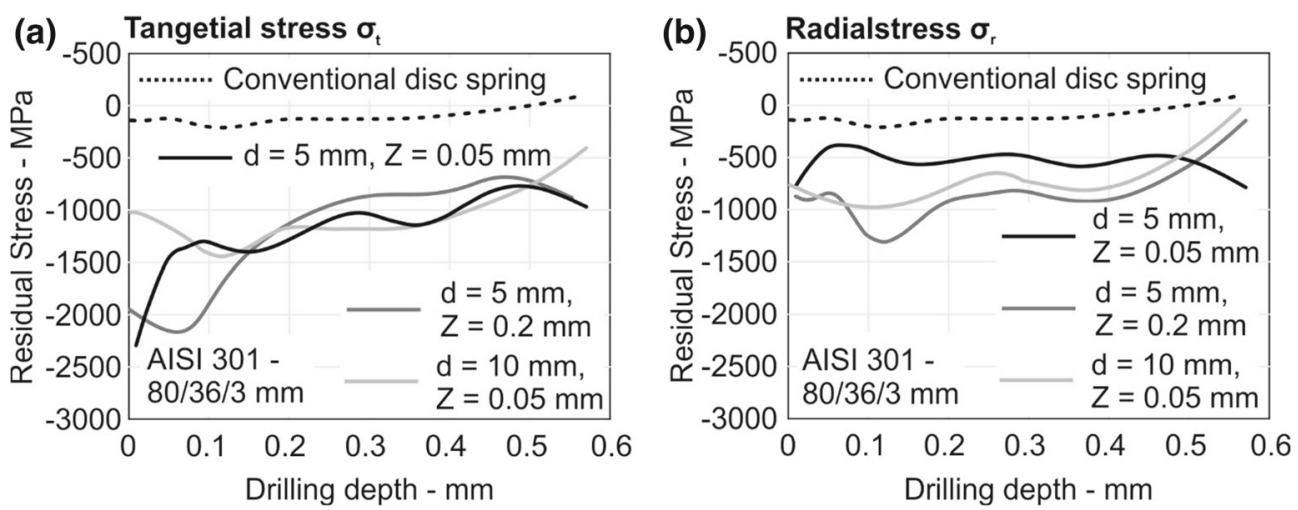

Fig. 15 Comparison of a Tangential residuals tresses b Radial residuals stresses for conventional and surface treated disk spring for varying tool diameter $\mathrm{d}$ and tool step-down $\mathrm{Z}$

For both strategies, a significant difference in the state of residual stresses is observed in comparison to the conventionally formed disk springs. A much higher magnitude of the compressive residual stresses in radial as well as tangential direction occurs toward the tool contact side. This in turn is due to the same deformation mechanism which replicates the deep-rolling effect for both strategies. The sheet blank and the disk springs are squeezed between the die and the forming tool, hence resulting in compressive residual stresses. The TRIP effect exhibited by the investigated steels further aids in the generation of the compressive residual stresses. Hence, due to the combined effect of plastic straining and martensite transformation, a high magnitude of the compressive residual stresses is found for the disk springs which are formed and surface treated by ISF in contrast to the conventional disk spring as can be seen in the Fig. 14.

In the next step, the residual stress generation mechanism was analyzed under the influence of changing process parameters for the disk springs of thickness $3 \mathrm{~mm}$, which are surface treated using strategy 2 . This is because more accurate residual stress values are obtained from the hole-drilling method for the thicker specimens. However, as the forming mechanism remains the same for both strategies, therefore, the results for the influence of the process parameters on the residual stresses will be valid for strategy 1 .

\subsection{Residual stress generation mechanism vs. process parameters}

\subsubsection{TPIF: residual stress generation mechanism vs. process parameters}

To determine the magnitude of the compressive residual stresses induced by varying the process parameters, the hole-drilling method was used to analyze the residual stresses in the disk springs of dimension $80 / 30 / 3 \mathrm{~mm}$ from strategy 2 . The measured residual stress values for varying tool diameter and tool step-down along the depth of the hole generated by hole-drilling method are presented in Fig. 15. A different contribution of the radial and tangential residual stresses is obtained by process parameter variation. The radial components of the residual stresses for surface-treated disk spring is significantly lower than that of the tangential components and nearly identical for each process parameter. The highest compressive residual stresses in the tangential direction are obtained for the smallest tool diameter.

Another methodology used to investigate the residual stress generation mechanism is based on cutting small strips in the radial and tangential direction from the disk springs. The strips cut along the tangential direction are $10 \mathrm{~mm}$ wide and cut from the middle section of the disk springs. The circular strips are further cut along the radial direction. The tensile and compressive residual stresses will cause the circular strips to either open or close, respectively. All circular strips close indicating a dominant compressive residual stress state. The highest geometric deviations,i.e., highest ring-closing corresponds to the highest magnitude of residual stresses. The magnitude of the ring-closing for different process parameter combinations is plotted in Fig. 16. It can be seen that residual stresses are highest for the smallest tool diameter and step-down, highest feed rate and contact force. These observations are in agreement with the hole-drilling measurements from Fig. 15.

Moreover, the curvature of the radially cut strips was measured and is plotted in Fig. 17 for varying tool diameter and tool step-down. Residual stress values measured using the hole-drilling method indicated a 

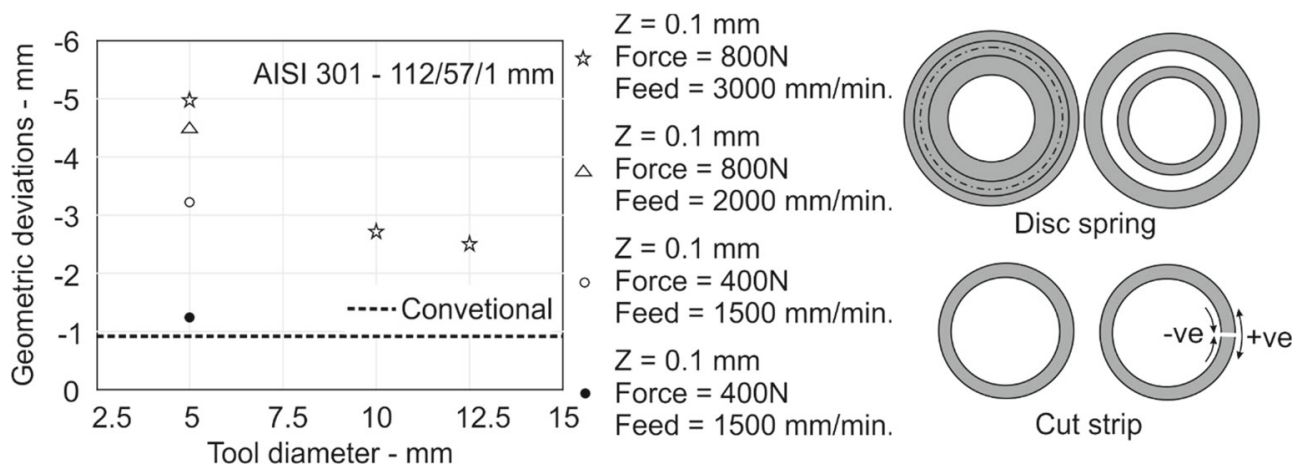

Fig. 16 Geometric deviations vs. tool diameter as a function of different process parameter combinations
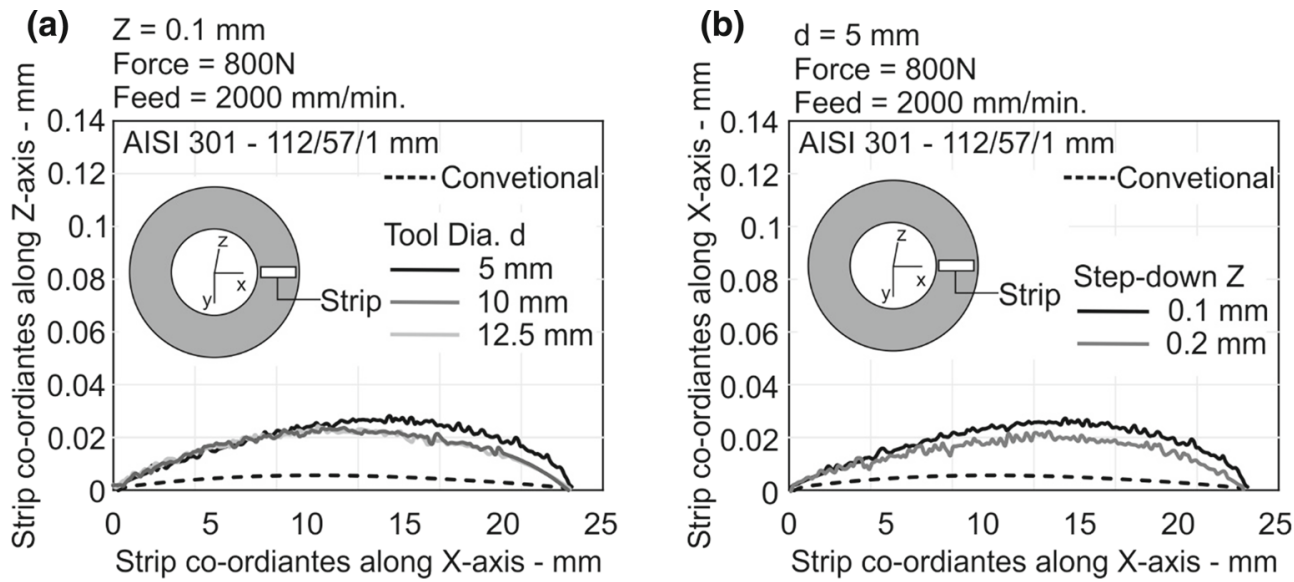

Fig. 17 The curvature of the radial cut strips for varying a Tool diameters $\mathbf{b}$ Tool step-down

similar magnitude of the residual stresses in the radial direction (Fig. 15b). This is validated as no significant differences between the curvature of the radially cut strips are observed.

\subsubsection{SPIF: residual stress generation mechanism vs. process parameters}

As described, the residual stresses state of the cone geometries manufactured by single point incremental forming are experimentally measured by XRD. The residual stresses are measured on both sides of the cone wall. The cone surface in contact with the forming tool is the bottom-face, the opposite side is the top-face of the cone. The location of the measuring point at a height of $22.5 \mathrm{~mm}$ in the middle of the cone wall is shown in Fig. 6b. The results of the measurements are shown in Fig. 18 for the bottom-face. Each point represents three measurements of the same spot. On the bottom-face of the cone wall, tensile residual stresses can be found for all parameters in the tangential direction (direction of the tool movement) and in the radial direction (transverse to the tool movement). With increasing step down increment, the amplitudes of tensile residual stresses in radial direction $\sigma_{\mathrm{r}}$ are decreasing (see Fig. 18a). From the highest residual stress value $\sigma_{r}=122 \pm 21 \mathrm{MPa}$ for $\Delta z$ $=1.875 \mathrm{~mm}$ the residual stress amplitudes are continuously decreasing with increasing step-down increment to a low level of tensile residual stresses $\sigma_{r}=36 \pm 12 \mathrm{MPa}$. Regarding the tensile residual stresses in the tangential direction (see Fig. 18b), they are in the same range as the residual stresses in the radial direction. The tangential residual stresses are increasing with decreasing step-down increment in an opposing trend. The change in the residual stress amplitudes with increasing tool step-down is less pronounced in the tangential direction $\left(\Delta \sigma_{t}=50 \mathrm{MPa}\right)$ than in the radial direction $\left(\Delta \sigma_{r}=150 \mathrm{MPa}\right)$. So, an influence of the process parameter step-down increment on the residual stress amplitude is measurable on the bottom-face.

The results of the measurement for the top-face are shown in Fig. 19. Compressive residual stresses can be found for all parameters in the tangential direction. The amplitudes of the compressive residual stress on the top-face are in the same range as the tensile residual stresses at the bottom-face. The change of residual stresses with increasing tool step-down is less pronounced on the top-face than on the bottom-face. The compressive 

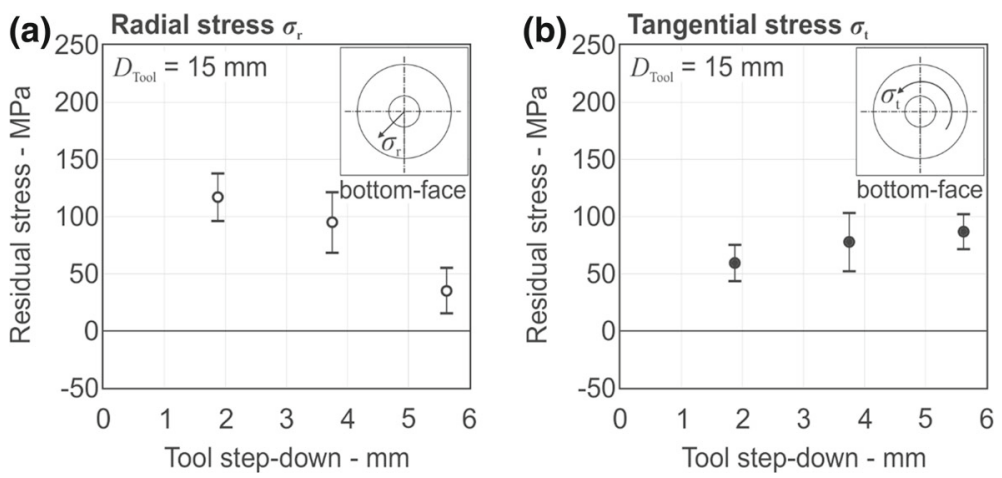

Fig. 18 Experimentally measured residual stresses in the middle of the cone wall at the bottom-face in a Tangential direction and b Radial direction
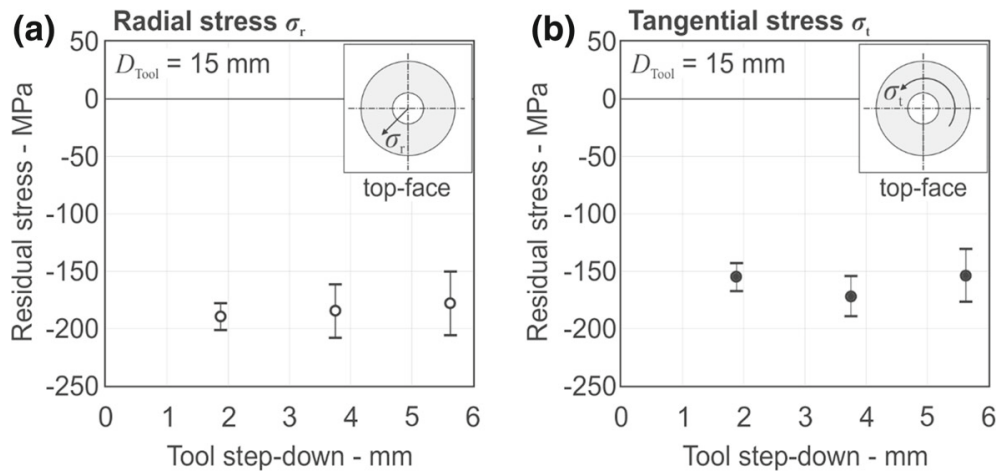

Fig. 19 Experimental measured residual stresses in the middle of the cone wall at the top-face in a Tangential direction and b Radial direction

residual stresses on the top-face in radial direction remain nearly constant with increasing tool step-down (see Fig. 19a). The same applies to the tangential direction with an amplitude of $175 \mathrm{MPa}$.

A comparison of the SPIF component geometries manufactured with three different process parameter sets is done by 3D digitalizer GOM® ATOS II. The geometry of all cone walls is compared to an ideal cone geometry, the desired CAD geometry. To compare the geometries, the CAD geometry was aligned along the symmetry axis of the formed component flange edges. The analysis of the geometric deviation is done by the GOM $®$ Inspect Software. The geometric deviation is defined as the maximum distance between the ideal cone wall and the cone wall of the formed component perpendicular to the surface direction. Figure 20 shows the resulting geometric deviation for the three different process parameter sets. The maximum deviation between the formed components and the ideal shape is in a range of $4 \mathrm{~mm}$ to $5 \mathrm{~mm}$. If the manufactured cone geometries are compared to each other, the maximum deviation is only $1 \mathrm{~mm}$. It can be thus stated, that a change in the process parameters in the considered range has no significant influence on the geometry of the final component formed by SPIF.

\subsection{Residual stresses vs. mechanical properties}

\subsubsection{TPIF: residual stresses vs. mechanical properties}

This section analyzes the influence of varying residual stresses on the mechanical properties of the disk springs. To quantify this, quasi-static disk compression tests were carried out and disk spring geometries were measured along a section. The spring forces are plotted in Fig. 21 a for the disk springs of dimension 80/36/3 mm, whose residual stresses were plotted in Fig. 15. The geometry of the disk springs after the surface treatment was also measured along a section and plotted in Fig. 21b. Based on the results of residual stress measurements, i.e., Fig. 15 and force-deflection curves, i.e., Fig. 21 a, the higher the compressive residual stresses, the higher the spring force. Hence, there is a positive effect of the induced residual stresses on the spring geometry. 


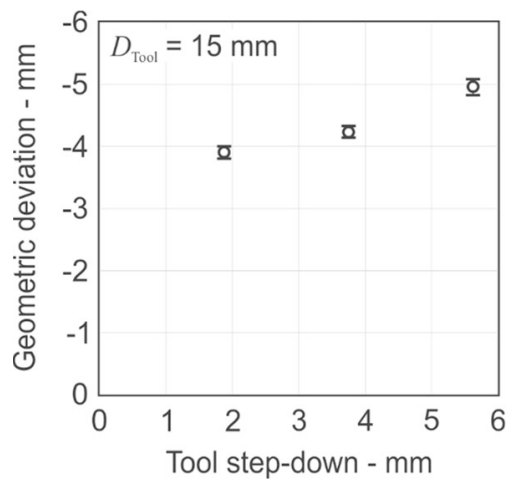

Fig. 20 Maximum geometric deviation of the cone wall compared to the ideal cone geometry

(a)

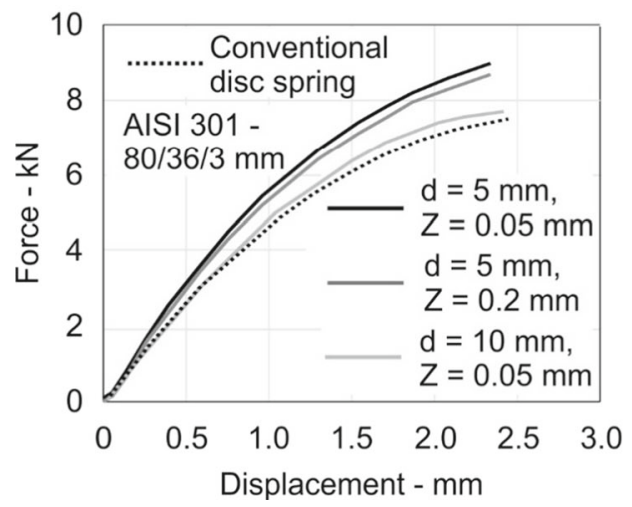

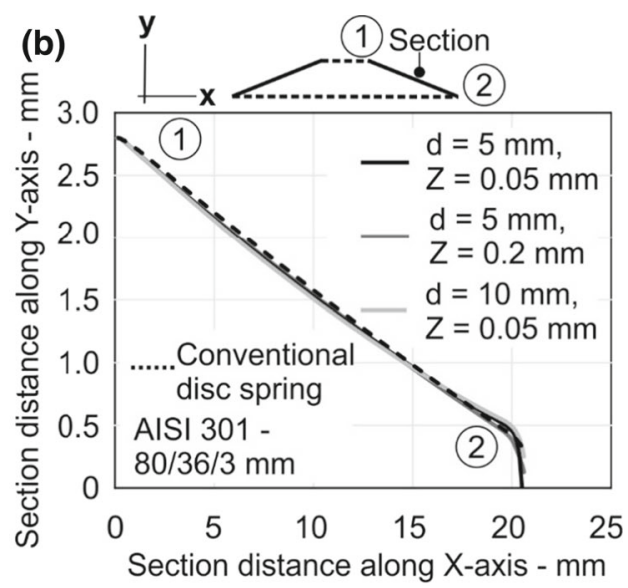

Fig. 21 a Spring forces b Disk spring contours for varying tool diameter and step-down

Furthermore, as no changes in the disk spring geometry are observed, therefore the increase in the spring forces is entirely due to residual stresses without the effect of geometric stiffness.

The spring forces and geometry of the disk springs surface-treated by varying tool diameter, contact force and tool step-down are plotted in Fig. 22. Based on the previous observations, the highest spring force should be for the smallest tool diameter and highest contact force. The smaller tool diameter and higher contact force lead to higher plastic strains due to a more concentrated deformation zone between the forming tool and the disk spring. Deformation Induced Martensite Transformation (DIMT) increases with higher plastic strain levels. Hence, the geometric deviations and spring force are higher for the smallest tool diameter and highest contact force as represented in Fig. 22. Furthermore, the effect of varying tool step-down is clarified. Although the measured residual values using the hole-drilling method are the same for different tool step-downs (see Fig. 15), the geometric deviations and spring force are higher for the smaller tool step-down as can be seen in Fig. 22. This is because the values provided by the hole-drilling method are measured locally at a point and not in the whole specimen, while surface treatment by a smaller tool step-down leads to more area being deformed and hence more global DIMT. This explains higher geometric deviation and spring force values for smaller tool step-down. Moreover, a difference in the geometry of the conventional and surface treated disk springs is observed. For all disk springs, an increase in the free height $l_{0}$ of the disk springs and curvature due to compressive residual stresses toward the bottom face, which was in contact with the forming tool appears. Therefore, the increase in spring force after ISF is due to the combined effect of induced residual stresses and changed geometry.

To only obtain the improvement in mechanical properties through residual stresses, an analytical approach according to DIN 2093 that predicts the spring force by taking the geometric stiffness into account is used. The free height of the disk spring is increased in an interval of $0.1 \mathrm{~mm}$ by keeping other parameters constant. The maximum spring force predicted by the analytical approach for the new geometries is recorded. The spring force of the initial geometry with a free height of $6.9 \mathrm{~mm}$ is used as a reference. The percentage increase in 
(a)

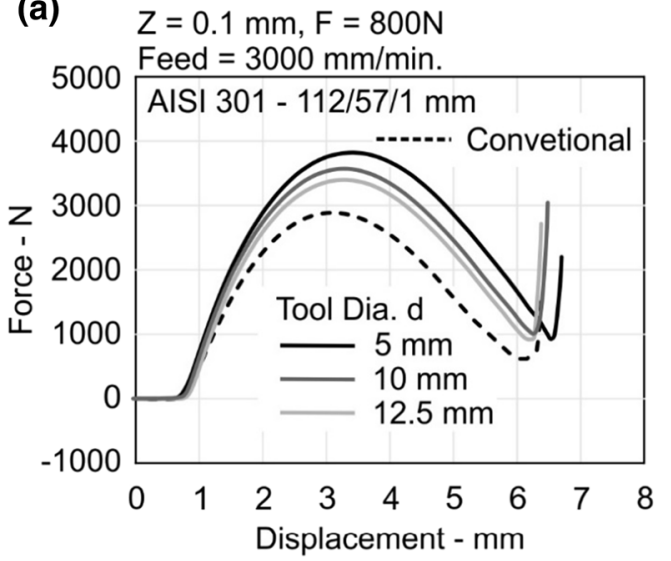

(c)

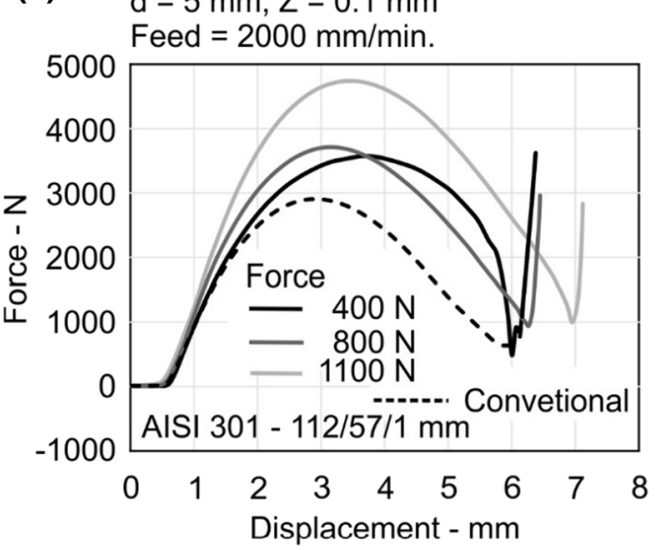

(e)

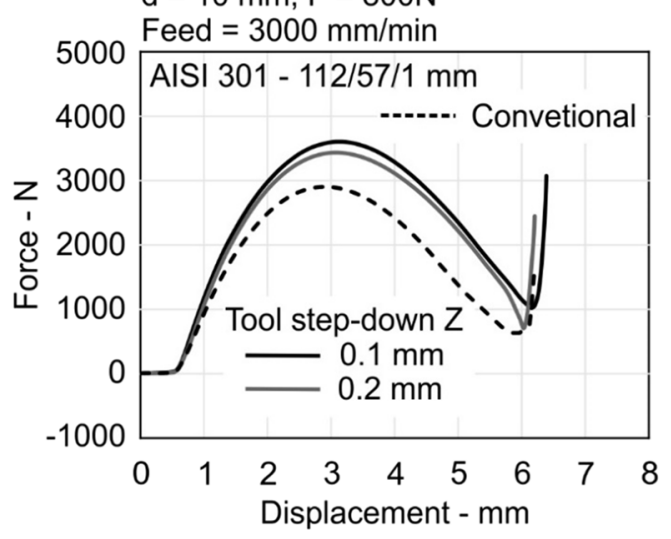

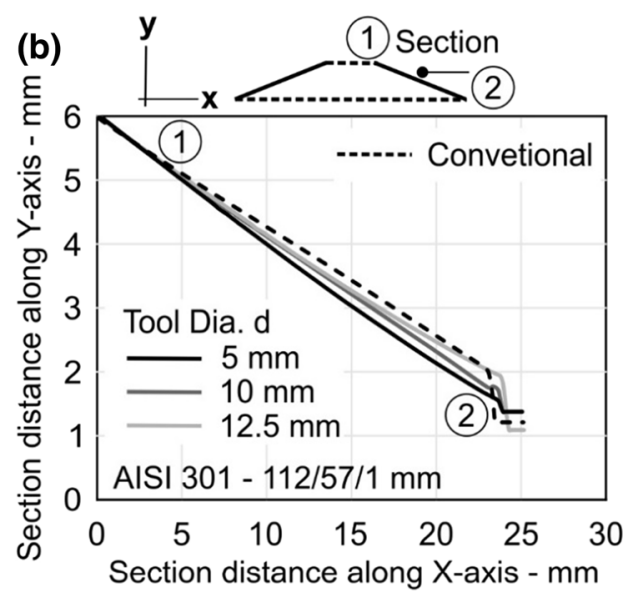

(d)
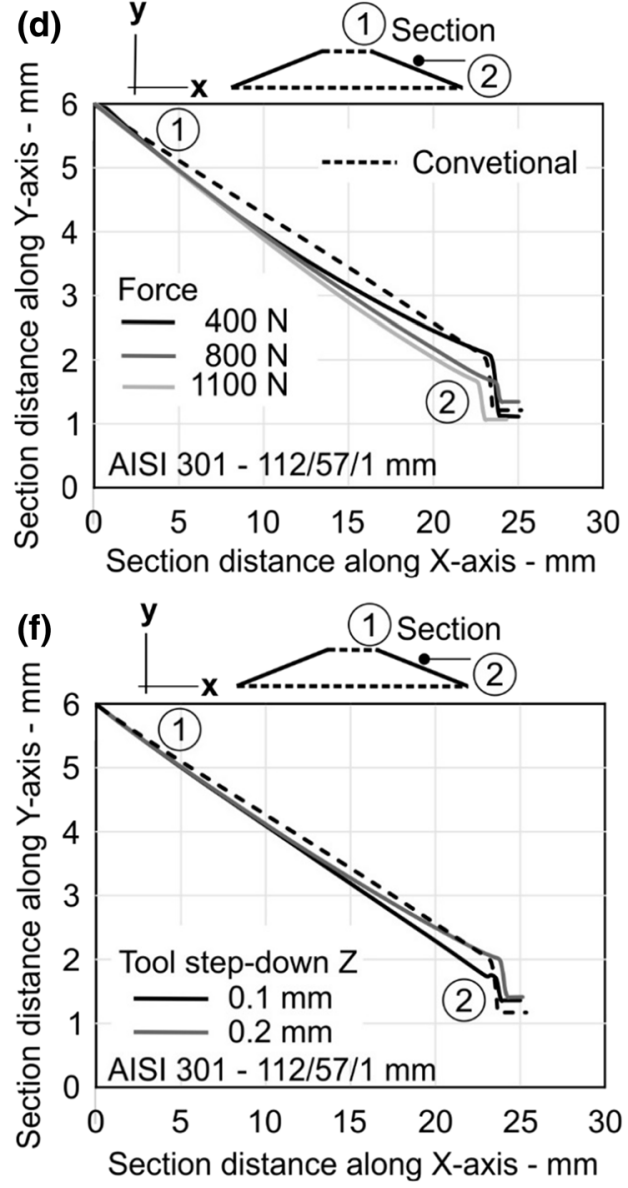

Fig. 22 a, c, e Spring forces b, d, e Disk spring contours for varying tool diameter, contact force and step-down

the spring force as a function of free height $l_{0}$ of the disk spring, i.e., only due to geometric stiffness is plotted in Fig. 23. Furthermore, the quasi-static compression tests in Fig. 13 were so designed that the disk spring is fully compressed between the two plates. Therefore, by measuring the displacement of each curve in Fig. 22(a, $\mathrm{c}, \mathrm{e})$, the free height of the disk spring is determined. Using the maximum spring force of the conventional disk spring as a reference, the percentage increase in the spring force for each curve from Fig. 22(a, c, e) is calculated and plotted against the free height $l_{0}$ in Fig. 23, i.e., the percentage increase in the spring force due to the combined effect of geometric stiffness and residual stresses. The difference between the curves is the contribution of the residual stresses. Hence, a significant contribution of the residual stresses in improving the 

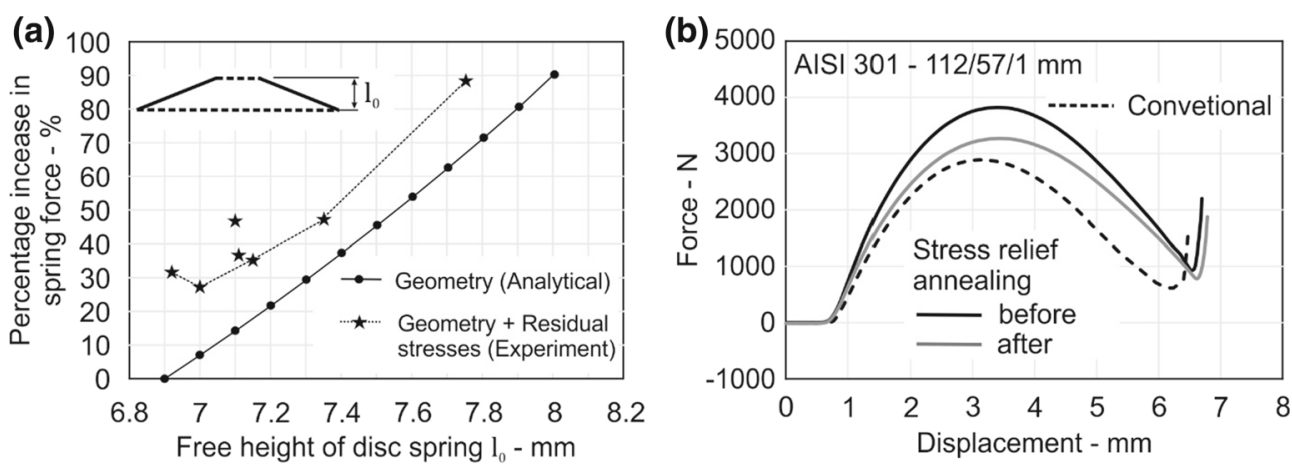

Fig. 23 a Percentage increase in the spring force as a function of the free height of disk spring $l_{0}$ due to geometry and combined effect of geometry and residual stresses $\mathbf{b}$ Validation of analytical approach by comparing spring forces before and after SRA

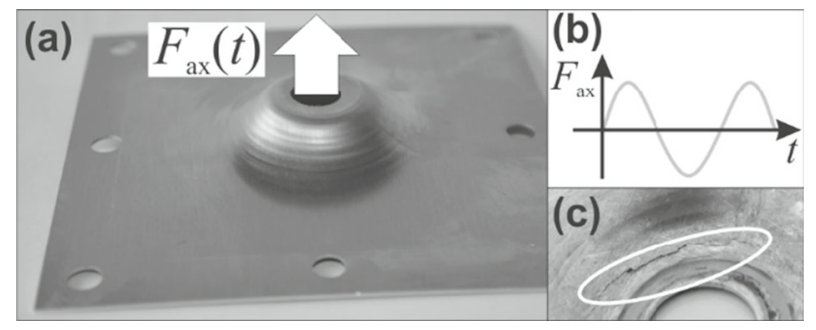

Fig. 24 a Fatigue test set-up b Fatigue strength of SPIF components (derived from [9])

mechanical properties is achieved. Further, the analytical approach was validated by Stress Relief Annealing (SRA) the surface-treated disk springs and performing disk compression tests. The force-displacement curves before and after SRA and for a conventional disk spring are presented in Fig. 22b. The difference between the before and after spring force curves is the contribution of the residual stresses, which is significant. At the same time, the spring force after SRA matches with the conventional disk spring. The spring force after SRA is only due to the geometric stiffness of the disk spring. Hence, the analytical approach is validated. The small difference between the conventional and after SRA curves is due to geometric changes caused by the uncontrolled release of elastic strains during SRA.

\subsubsection{SPIF}

It was shown that the resulting residual stress state of a formed component can be influenced by the process parameters of the SPIF process. Especially under cyclic loadings, residual stresses can have a significant influence on the fatigue strength of a component. To evaluate the influence of near-surface residual stresses induced by SPIF on the mechanical properties of the formed components, a cyclic loading test can be used to quantify the effect. Maaß et al. [9] performed fatigue tests with truncated cone geometries manufactured by SPIF. The specimens are cyclically loaded with an applied force of $F=600 \mathrm{~N}$ and a frequency of $f=10 \mathrm{~Hz}$ until the specimen fails by crack initiation (Fig. 24a). The used process parameters are in the same range as the presented parameter sets in this work. Although the geometries analyzed are smaller cone geometries, the results can be transferred to the findings of this paper. The largest tool step-down leads to the highest fatigue strength. Compared to this benchmark value, smaller tool step-downs leads to decreased fatigue strength. When reducing the tool step-down, the performance of the component under cyclic load corresponds to less than $60 \%$ of the components formed with larger step-downs (Fig. 24 b). The process parameters of the SPIF process therefore significantly influence the mechanical properties of the formed component. 


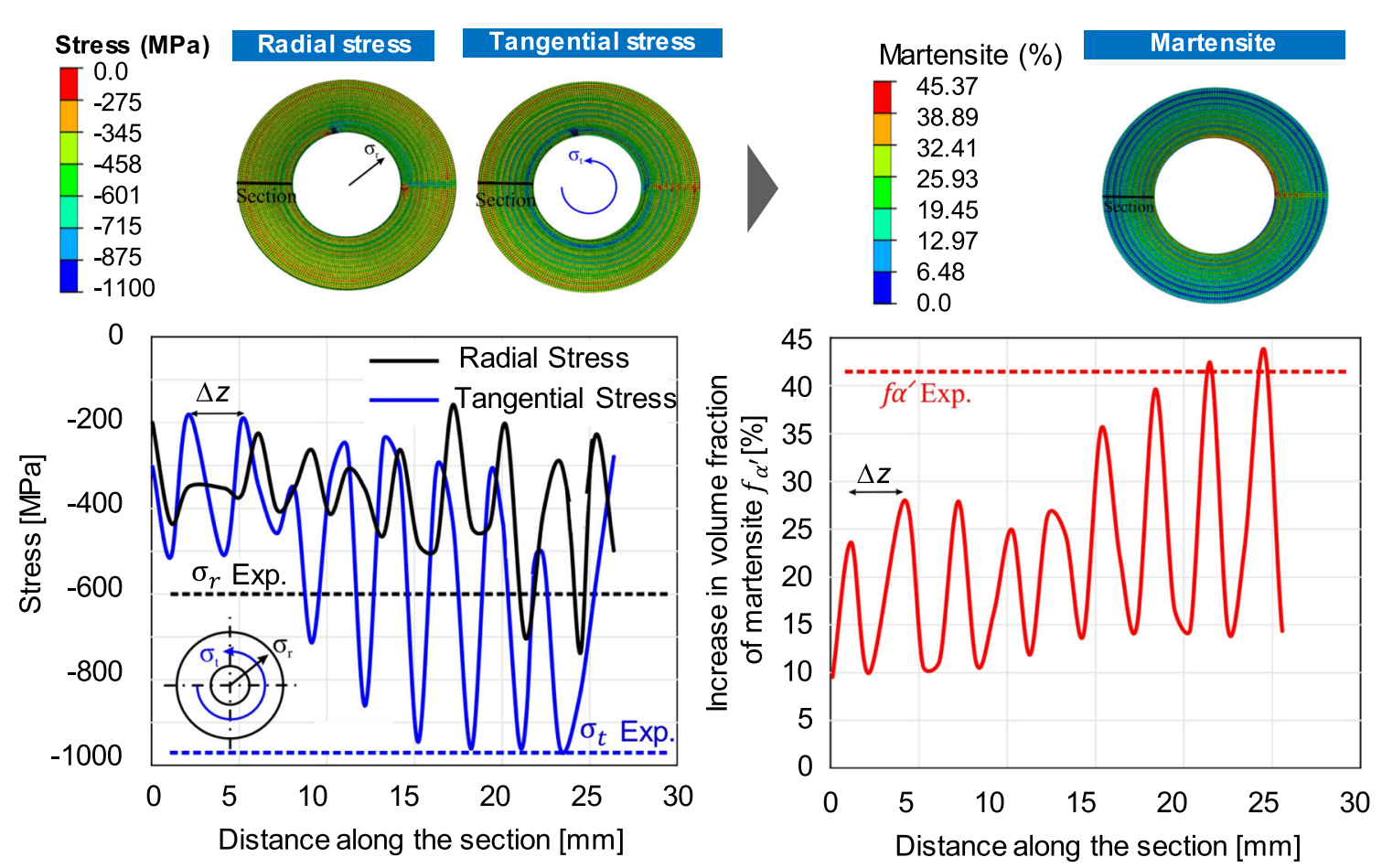

Fig. 25 a Residual stresses along a section in disk springs in radial and tangential direction b Percentage martensite volume fraction along a section in disk sprig

\subsection{Numerical results}

\subsubsection{TPIF: prediction of the residual stresses}

The main aim was to develop a numerical model capable of predicting the accurate residual stress state for the TPIF process, which involves a complex forming mechanism of continuous bending/unbending and for selected steel that exhibits the TRIP effect. The results from the numerical model for a single TPIF simulation according to the model (see Fig. 11) are presented. After the numerical simulation of the disk springs, respective springback simulation was performed. A cylindrical coordinate system was used to obtain the radial and tangential components of the residual stresses. The stresses and the martensite content were plotted on a section placed on the tool contact side as shown in Fig. 25a and b.

Based on the geometrical dimension of the disk spring and the tool step-down of $0.4 \mathrm{~mm}$, the forming tool produces 9 loops over the disk spring. The results in Fig. 25 show certain peaks and valleys. The peaks then corresponds to the area over which the forming tool moves and the valleys corresponds to the area, over which forming tool does not moves. In addition, the displacement-controlled trajectory of the forming tool produces different plastic deformation in different areas, therefore the respective distribution of residual stresses and martensitic content is inconsistent. To validate the numerical simulation, the residual stresses through hole-drilling method and martensitic content through Feritscope was measured at a specified point. The experimentally measured values are plotted as dotted lines together with numerically determined martensite content and residual stresses in both directions in Fig. 25a and b. The residual stresses measured at the center of the bottom face by hole-drilling method are 975 and $600 \mathrm{MPa}$ along the radial and tangential direction. The martensite content at the same location is found to be $42 \%$. For numerical simulations, the location where the martensite content is $42 \%$, the respective residuals tress in radial and tangential direction are 960 and $700 \mathrm{MPa}$. Hence, for a given martensite content, similar magnitude of residual stresses is found from experiment and numerical simulation. However, further investigations and comparisons are necessary to completely validate the numerical model. 

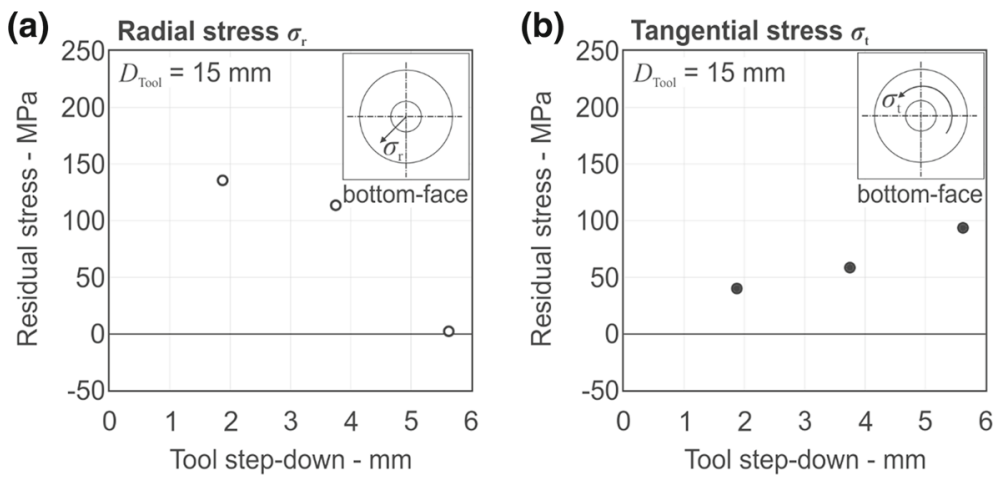

Fig. 26 Numerically evaluated residual stresses in the middle of the cone wall at the bottom-face in a Tangential direction and b Radial direction
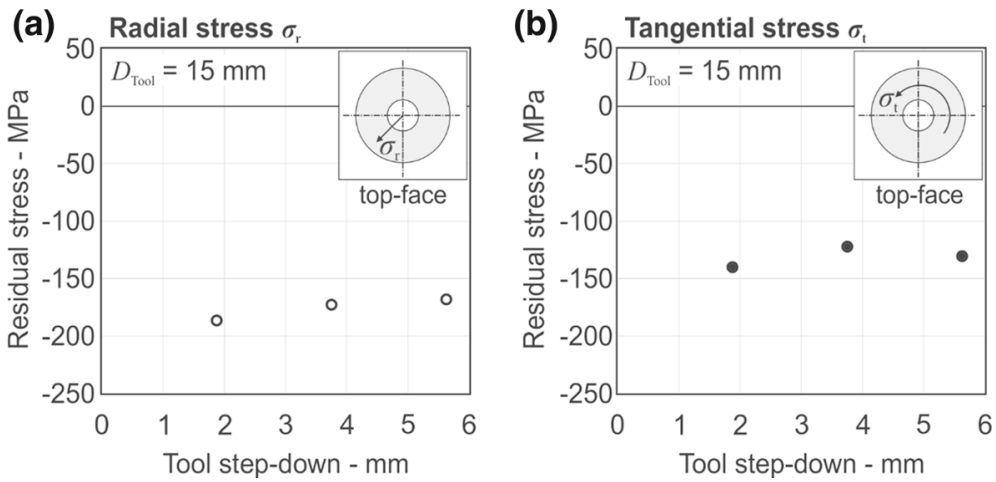

Fig. 27 Numerically evaluated residual stresses in the middle of the cone wall at the top-face in a Tangential direction and b Radial direction

\subsubsection{SPIF: prediction of the residual stresses}

The numerical model of the SPIF process built-in Abaqus is also used to analyze the near-to-surface residual stresses of the formed component depending on the process parameters. The evaluation points of the numerical model should be positioned close to the XRD measurement point to ensure comparability.

According to the XRD measurements, the near-to-surface residual stress components are output on the top and bottom faces of the truncated cone geometries. Figure 26a presents the results for the tool-face perpendicular to the tool movement. With increasing tool step-down the tensile residual stresses decrease. For larger tool-step downs the residual stresses in the radial direction almost disappear. In an opposing trend, the residual stresses in tool direction (see Fig. 26b) increase with increasing tool-step down. The numerically evaluated amounts of residual stresses are qualitatively and quantitatively in good accordance with the experimental results (see Fig. 18).

Regarding the numerical results on the tool-averted top-face of the truncated cone, the numerical results are presented in Fig. 27. They are also in good accordance with the experimental results (compare Fig. 19). Similar to the experimental results, the stress amplitudes in the radial direction slightly increase in a small range. The stress amplitudes in the tangential direction are stationary. In summary, the residual stress prediction of the used numerical procedure is accurate. The overall difference between the numerical and experimental results can is $14 \%$, which is less than the experimentally observed scatter.

\section{Discussion}

The main aim of this chapter was to provide an analysis of the targeted generation and utilization of the residual stresses for the two most commonly utilized variants of the ISF, i.e., SPIF and TPIF. In addition, numerical models to accurately predict the residual stresses for these two ISF variants were to be developed. 
In the case of TPIF with a negative die, it is found that due to the deep-rolling effect created by the squeezing of the sheet blank between the die and the forming tool, the compressive residual stress state is the dominant state for TPIF. Further, irrespective of the TPIF variant, i.e., with a positive or negative die, it can be stated based on the forming mechanism that a high magnitude of the compressive residual stresses will occur toward the tool contact side. However, this cannot be stated for the TPIF variant with a partial die as no double-sided contact is present for this variant and as no squeezing or deep rolling-like effect is produced. The benchmark geometry of the disk springs was intentionally selected to not only study the residual stress generation mechanism but also to prove that the high residual stresses of ISF can be positively utilized to improve the mechanical properties. By using ISF as integrated forming and surface treatment technique, it is shown that the residual stresses can be targetedly controlled and utilized to improve the part performance. The investigations on the residual stress generation mechanism indicate a significant presence of the residual stresses and their contribution to improving the mechanical properties is proved. These observations open new windows for ISF to be applied as an alternative surface treatment and integrated forming approach. These observations in combination with control of the ISF process can be used to achieve localized properties on a global scale, for example, localized hardening in the selected areas or control over radial or tangential residual stress components to achieve stiffness in the desired direction, for examples, as required by the disk springs used in the vibration actuators [24].

In terms of numerical simulation of TPIF, an accurate prediction of martensite content and the residual stresses is obtained. The model can further be employed to investigate the austenite and martensite phase distribution and their effect on the resulting residual stresses. However, previous forming operation involved from manufacturing to final rolling of the sheet blanks also significantly control the properties like microstructure and residual stress gradients. This effect must also be taken into consideration to further improve the numerical model. This is possible by initializing variables such as initial martensite content, stress gradients and plastic strain for the initial sheet blank in numerical simulation and then carrying out ISF simulation. This allows recording complete loading histories and their effect on mechanical properties and microstructure. This can then used to accurately predict and control part properties, for example, disk spring properties like spring force and fatigue life.

In the case of SPIF, the initially residual stress-free material develops a significant amount of residual stresses. It is found that, depending on the used process parameters, the near-to-surface residual stresses can be adjusted. On the tool-face of the formed cone geometry, tensile residual stresses are generated. On the toolaverted face, compressive residual stresses occur. Regarding the analyzed single-phase material aluminum alloy 5083, the residual stress state of a formed component can be adjusted in a wide range. The amplitude on the tool-face can be varied between no significant residual stresses to values near the initial yield stress of the material. Depending on the achieved residual stress state, the mechanical properties of the formed component are significantly influenced.

\section{Summary and conclusion}

The main aim of the current study was to provide an in-depth analysis of the targeted generation and utilization of the forming induced residual stresses by SPIF and TPIF variants of the ISF process. The main conclusions for each variant are:

\subsection{TPIF}

- The dominant residual stress state generated by the TPIF variant is the compressive residual stress state in both directions of tool motion.

- Two different strategies are used to provide an in-depth analysis of the residual stress generation mechanism for TPIF. The effect of different process parameters is analyzed. The smallest tool diameter and tool stepdown and highest contact force and feed rate produce the highest compressive residual stresses.

- An improvement in the mechanical properties of the disk springs is recorded. Hence, the compressive residual stresses generated by TPIF can be used to improve the mechanical properties.

- Developed knowledge can be used to produce parts with localized properties on a global scale. For example, localized hardening or control over the radial or tangential residual stress components to achieve stiffness in the desired direction 
- A numerical model is presented and validated which can be used to accurately simulate the TRIP effect as well it provides a quantitative validation of the residual stresses.

\subsection{SPIF}

- The dominant residual stress state generated by the SPIF variant is the compressive residual stress state on the tool-averted face and tensile residual stresses on the tool-face.

- It is shown that the near-to-surface residual stress state can be adjusted by the selected tool step-down in SPIF.

- Depending on the generated residual stress state by SPIF the mechanical properties of the formed parts can be improved.

- A numerical model for the SPIF process is presented and validated, which can be used to accurately simulate the residual stress development.

- This knowledge can be used to produce a part with localized properties on a global scale especially regarding residual stress cased failure in cyclic loaded parts.

Acknowledgment The authors would like to thank the German Research Foundation DFG for the support of the depicted research within the priority program 'SPP2013' through project no. 'BA 4253/6-2', project no. 'WA 1672/31-2' and project no. 'TE 508/67-2'.

Funding Open Access funding enabled and organized by Projekt DEAL.

\section{Declarations}

Conflict of interest On behalf of all authors, the corresponding author states that there is no conflict of interest.

Open Access This article is licensed under a Creative Commons Attribution 4.0 International License, which permits use, sharing, adaptation, distribution and reproduction in any medium or format, as long as you give appropriate credit to the original author(s) and the source, provide a link to the Creative Commons licence, and indicate if changes were made. The images or other third party material in this article are included in the article's Creative Commons licence, unless indicated otherwise in a credit line to the material. If material is not included in the article's Creative Commons licence and your intended use is not permitted by statutory regulation or exceeds the permitted use, you will need to obtain permission directly from the copyright holder. To view a copy of this licence, visit http://creativecommons.org/licenses/by/4.0/.

\section{References}

1. Peter, I., Fracchia, E., Canale, I., et al.: Incremental sheet forming for prototyping automotive modules. Procedia Manuf. 32, 50-58 (2019). https://doi.org/10.1016/j.promfg.2019.02.182

2. Jeswiet, J., Micari, F., Hirt, G., et al.: Asymmetric Single Point Incremental Forming of Sheet Metal. CIRP Ann. 54, 88-114 (2005). https://doi.org/10.1016/S0007-8506(07)60021-3

3. Emmens, W.C., van den Boogaard, A.H.: An overview of stabilizing deformation mechanisms in incremental sheet forming. J. Mater. Process. Technol. 209, 3688-3695 (2009). https://doi.org/10.1016/j.jmatprotec.2008.10.003

4. Bambach, M., Taleb Araghi, B., Hirt, G.: Strategies to improve the geometric accuracy in asymmetric single point incremental forming. Prod. Eng. Res. Devel. 3, 145-156 (2009). https://doi.org/10.1007/s11740-009-0150-8

5. Maqbool F, Bambach M (2017) A modular tooling set-up for incremental sheet forming (ISF) with subsequent stress-relief annealing under partial constraints. In: Author(s), p 80010

6. Hajavifard, R., Maqbool, F., Schmiedt-Kalenborn, A., et al.: Integrated forming and surface engineering of disc springs by inducing residual stresses by incremental sheet forming. Mater. (Basel) (2019). https://doi.org/10.3390/ma12101646

7. Maqbool, F., Hajavifard, R., Walther, F., et al.: Engineering the residual stress state of the metastable austenitic stainless steel (MASS) disc springs by incremental sheet forming (ISF). Prod. Eng. Res. Devel 13, 139-148 (2019). https://doi.org/10.100 7/s11740-018-0864-6

8. Maßß, F., Hahn, M., Tekkaya, A.E., et al.: Forming mechanisms-related residual stress development in single point incremental forming. Prod. Eng. Res. Devel 13, 149-156 (2019). https://doi.org/10.1007/s11740-018-0867-3

9. Dobecki M, Hahn M, Maaß F et al. (2019 - 2019) Setting Component Properties in Incremental Forming. In: Contributed Papers from MS\&T19. TMS, pp 1176-1182

10. Tanaka S, Nakamura T, Hayakawa K et al. (2007) Residual Stress In Sheet Metal Parts Made By Incremental Forming Process. In: AIP Conference Proceedings. AIP, pp 775-780 
11. Radu, C., Herghelegiu, E., Tampu, N.C., et al.: The residual stress state generated by single point incremental forming of aluminum metal sheets. AMM 371, 148-152 (2013)

12. Radu, C., Tampu, C., Cristea, I., et al.: The effect of residual stresses on the accuracy of parts processed by SPIF. Mater. Manuf. Processes 28, 572-576 (2013). https://doi.org/10.1080/10426914.2013.763967

13. Jiménez, I., López, C., Martinez-Romero, O., et al.: Investigation of residual stress distribution in single point incremental forming of aluminum parts by X-ray diffraction technique. Int J Adv Manuf Technol 91, 2571-2580 (2017). https://doi.org/ 10.1007/s00170-016-9952-y

14. Shi, X., Hussain, G., Butt, S.I., et al.: The state of residual stresses in the $\mathrm{Cu} / \mathrm{Steel}$ bonded laminates after ISF deformation: An experimental analysis. J. Manuf. Process. 30, 14-26 (2017). https://doi.org/10.1016/j.jmapro.2017.09.009

15. Maqbool, F., Bambach, M.: Experimental and numerical investigation of the influence of process parameters in incremental sheet metal forming on residual stresses. JMMP 3, 31 (2019). https://doi.org/10.3390/jmmp3020031

16. Doman, Y.: Influence of residual stress on the load-deflection curve of diaphragm springs for automobile clutches. JSAE Rev. 24, 197-203 (2003). https://doi.org/10.1016/S0389-4304(02)00299-0

17. DIN EN 15305 (2009) Non-destructive testing - Test method for residual stress analysis by X-ray diffraction DIN EN 15305 : 2009-01

18. Macherauch, E., Müller, P.: Das sin2- $\Psi$ Verfahren von röntgenographischenEigenspannungen. Zeitschrift für angewandte Physik 13, 305-312 (1961)

19. Chaboche, J.L., Rousselier, G.: On the Plastic and Viscoplastic Constitutive Equations-Part I: Rules Developed With Internal Variable Concept. J. Pressure Vessel Technol. 105, 153-158 (1983). https://doi.org/10.1115/1.3264257

20. Guiheux, R., Berveiller, S., Kubler, R., et al.: Martensitic transformation induced by single shot peening in a metastable austenitic stainless steel 301LN: Experiments and numerical simulation. J. Mater. Process. Technol. 249, 339-349 (2017). https://doi.org/10.1016/j.jmatprotec.2017.06.015

21. Olson, G.B., Cohen, M.: A mechanism for the strain-induced nucleation of martensitic transformations. J. Less Common Metals 28, 107-118 (1972). https://doi.org/10.1016/0022-5088(72)90173-7

22. Hedström, P., Lindgren, L.E., Almer, J., et al.: Load partitioning and strain-induced martensite formation during tensile loading of a metastable austenitic stainless steel. Metall. Trans. 40, 1039-1048 (2009). https://doi.org/10.1007/s11661-0099807-3

23. Lemaitre, J., Chaboche, J.-L.: Mechanics of solid materials. Cambridge University Press (2012)

24. Hoppe, F., Knoll, M., Götz, B., et al.: Reducing uncertainty in shunt damping by model-predictive product stiffness control in a single point incremental forming process. AMM 885, 35-47 (2018)

Publisher's Note Springer Nature remains neutral with regard to jurisdictional claims in published maps and institutional affiliations. 